\title{
Can loss aversion shed light on the deflation puzzle?
}

\author{
Jenny N. Lye and lan M. McDonald* \\ University of Melbourne, Australia
}

This paper argues that the application of loss aversion to wage determination can explain the deflation puzzle: the failure of persistently high unemployment to exert a persistent downward impact on the rate of inflation in money wages. This is an improvement on other theories of the deflation puzzle which simply assume downward wage rigidity, namely the hysteresis theory, the lubrication theory and the efficiency wage theory. The paper presents estimates that support the loss-aversion explanation of the deflation puzzle for both the US and Australia. Furthermore, our estimation approach gives a more precise estimate of the potential rate of unemployment than does the natural rate approach and reveals potential rates of unemployment for the US and Australia at the end of 2017 of about 4 per cent and 3.3 per cent respectively.

Keywords: unemployment, inflation, Phillips curve, hysteresis, loss aversion, behavioural macroeconomics

JEL codes: $E 12, E 24, E 31, E 71$

'[I]n contrast to the accelerationist hypothesis, very high unemployment did not lead to lower and lower inflation, but rather just to ongoing low inflation.'

Olivier Blanchard (2018, p. 98)

'[A] community in which money wages fall without limit so long as unemployment exists is very unlike the real world.'

Joan Robinson (1937, p. 122)

\section{INTRODUCTION}

The deflation puzzle is the failure of persistently high unemployment to exert a persistent downward impact on the rate of inflation. This paper investigates the role that loss aversion might play in explaining the existence of the deflation puzzle. We briefly review several existing explanations of the deflation puzzle, namely the hysteresis model of Blanchard, Cerruti and Summers (2015), hereafter BCS, the lubrication theory of Schultze (1959), Tobin (1972) and Akerlof et al. (1996), and the efficiency wage theory of Shapiro and Stiglitz (1984). We point out that to explain the deflation puzzle, each of

* We thank Jeff Borland, Tim Robinson, Thomas Palley and two anonymous referees for helpful comments. 
these theories relies on an unexplained assumption of downward money-wage rigidity. They have a missing element. We then show that feelings of loss aversion by workers about cuts in money wages relative to reference money wages has the potential to explain the deflation puzzle.

We present estimates for the US and Australia of the Phillips curve relation between inflation and unemployment using a specification that allows for the existence of the influence of loss aversion. The estimating model we use was originally developed in Lye et al. (2001). It extended the estimation model in Gruen et al. (1999) to include the influence of loss aversion in wage setting. ${ }^{1}$ The estimates supported the importance of loss aversion in explaining the deflation puzzle. The new estimates reported here give further support to the importance of loss aversion. They are shown to compare favourably with the estimates of the natural rate model and estimates by BCS of the hysteresis non-accelerating inflation rate of unemployment (NAIRU).

As introduced by Bhaskar (1990), applying the concept of loss aversion and the prospect theory of Kahneman and Tversky (1979) to wage setting provides a behavioural microfoundation to resolve the deflation puzzle. If loss-averse relative to a reference wage, workers would dislike a lower wage with a greater intensity than they would like a wage above the reference wage. Thus, there would be a discontinuity in the worker's utility function around the reference wage. When combined with bargaining theory and/or efficiency wage theory, the feeling of loss aversion by workers implies a range of wages and thus a range of rates of unemployment in which wages are determined by the worker's reference wage. That implication suggests the possibility that if reference wages have a degree of independence from the rate of unemployment then loss aversion can resolve the deflation puzzle.

The practical importance of worker resistance to wage cuts was emphasised by Keynes (1936) and Robinson (1937). McDonald (2019) relates their ideas to loss aversion. It will be seen that their discussion of wage-setting contains insights which although being neglected by the subsequent mainstream macroeconomic literature are relevant for the loss-aversion approach.

The loss-aversion theory implies a theoretical mechanism to determine the lower limit to the range of unemployment rates within which reference wages determine actual wages. We call this rate of unemployment 'umin'. At unemployment rates below umin, the relatively buoyant state of the labour market will induce workers and/or employers to press for wages that exceed the workers' reference wages. This lower limit can be related to labour supply factors such as unemployment benefits and trade union power. ${ }^{2}$

In recent years it appears that ongoing low wage inflation has not kept up with the growth of money output per worker, nor indeed with Consumer Price Index (CPI) inflation - see for example Krueger (2018) for the US and Chua and Robinson (2018) and Isaac (2018) for Australia. Both Krueger and Isaac argue that employer

1. Gruen et al. (1999), following Phillips (1958), specified a convex short-run Phillips curve but, like Phillips, offered no theoretical explanation for the inflation-unemployment relation to be flat at high rates of unemployment.

2. Loss-aversion theory also implies an upper limit to the range of unemployment rates within which reference wages determine actual wages. We call this 'umax'. However, support for the empirical existence of umax is not strong and so for this paper we use a two-regime specification, that is a low-unemployment regime and a high-unemployment regime. A three-regime specification, with low-, intermediate- and high-unemployment regimes, returned an implausibly low value for the effect of unemployment on inflation in the low-unemployment regime. 
power has increased and worker power has decreased and this may be responsible for weak nominal wage growth. With the loss-aversion theory, if the reference wage is thought of as influenced by workers' aspirations then decreases in power may cause workers to trim their ambitions and their reference wages. We extend our earlier loss-aversion model to test for this idea by allowing the change in union power to have a direct influence on wage outcomes.

The deflation puzzle can also be resolved by the kinked demand curve for output see for example Woglom (1982) and McDonald (1987). These papers favour using customer-market analysis and the associated asymmetric information to justify a kink in the demand curve; existing customers find out quickly about the price changes of a particular seller whereas potential customers find out relatively slowly. ${ }^{3}$ As a result, price increases lead quickly to a loss of customers and thus sales while price decreases lead to a much slower positive response of sales, due to the reliance on the news of a price decrease spreading slowly to potential customers. Both the lossaversion approach and the customer-market approach share the characteristic of a kink in the objective function of some of the agents: loss aversion causing a kink in the utility function of workers and customer markets causing a kink in the revenue function of sellers.

Loss aversion and customer markets are not alternatives: they can be combined see Lye et al. (2001) and McDonald and Sibly (2005). And their combination leads to a wider range of equilibria.

Palley (1990) presents an explanation of downward wage rigidity which extends the efficiency wage theory to include behavioural elements, thereby addressing the missing element in efficiency wage theory. Palley argues that the employee-employer relationship is 'antagonistic' in that the employer is always on the look-out to reduce wages. Because of this, and the employee's uncertain knowledge of her marginal revenue product, any wage reduction would be treated with suspicion and cause the employee to punish the employer by reducing effort. The ability to punish the employer may be strengthened by tacit coordination by employees, aided by their feelings of identification with each other underscored by the social nature of work.

Furthermore, Palley (2012) applies his theory of downward nominal wage rigidity to the lubrication theory, thereby addressing our criticism of the applications of that theory.

We see loss aversion as strengthening Palley's argument. The intensity of the dislike of wage cuts would cement the tacit bonds amongst employees. Furthermore, the concept of a reference wage adds an important dimension, enriching the study of wage rigidity. For example, the idea that the reference wage will move with expected inflation extends the study of wage rigidity to situations of ongoing inflation.

The plan of the paper is as follows. In Section 2 we discuss the missing element in the hysteresis model of Blanchard et al. (2015), the lubrication theory of Schultze (1959), Tobin (1972) and Akerlof et al. (1996), and the efficiency wage theory of Shapiro and Stiglitz (1984), that is the lack of a theory of downward money wage rigidity. In Section 3 we explore the potential of loss aversion by workers with respect to their reference wage to explain the deflation puzzle. In Section 4 we present our estimates for the US and Australia of the two-regime, loss-aversion-based model of the inflation-unemployment relation and compare them with our estimates of the one-regime, natural rate version of the model and the BCS estimates of their hysteresis model. Section 5 concludes the paper.

3. Sibly (2002) uses loss aversion to derive the customer-market asymmetry: he proposes that customers suffer loss aversion if the price of their habitual supplier is increased. 


\section{THE MISSING ELEMENT IN THREE THEORIES OF THE DEFLATION PUZZLE}

\subsection{Hysteresis}

BCS argue that labour market hysteresis may be caused by unemployed workers dropping out of the labour force or becoming unemployable. ${ }^{4}$ This explanation of hysteresis pivots around the inability of unemployed workers to provide effective competition for the employed. The unemployed either cease to seek employment or become ineffective as employees. In discussions of this behavioural pattern, the de-skilling of unemployed people is often emphasised. ${ }^{5}$

However, the BCS model lacks a convincing explanation for the lack of deflationary pressure at high rates of unemployment. A loss by the unemployed of the ability to compete is an incomplete explanation of downward wage rigidity because it doesn't explain why these workers do not negotiate lower wages that reflect their loss of skills and/or job-finding ability. Thus, it relies on an unexplained rigidity in wages. For example, if an unemployed worker has lost 10 per cent of his productivity due to de-skilling, why then does he not negotiate a job with a 10 per cent reduction in wages? If on-the-job activity is expected to restore his skills then the negotiated wage reduction could be temporary. One may also ask why a worker threatened with the loss of his job and anticipating the possibility of de-skilling does not negotiate a downward adjustment in wages to prevent the loss of his job. ${ }^{6}$

The BCS model of the hysteresis natural rate has a second deficiency in that as specified it does not determine limits to the range of hysteresis. The lack of a theory of the lower limit implies a lack of guidance for policy-makers on the non-inflationary potential level of activity and thus a lack of information on the output gap, a standard ingredient in policy rules such as the Taylor rule. BCS recognise this when they say, following an increase in the actual rate of unemployment, 'the unemployment gap, and by implication inflation, will give a misleading signal about the degree of underutilization of resources in the economy' (BCS, p. 25). Their point is that inflation is not decreasing even though resources are underutilised.

In practice, the idea of a minimum rate of unemployment below which the hysteresis natural rate cannot be pushed by expanding aggregate demand without causing inflationary pressure is compelling. The estimation of the hysteresis natural rate as specified by BCS does allow implicitly for the influence of labour market factors in as far

4. They also mention three other causes of hysteresis unrelated to labour market activity: firms may invest less, reducing the capital stock; firms may do less research and development; reallocation and the associated productivity growth may suffer in a recession.

5. In an earlier analysis, Blanchard and Summers (1986), the emphasis was on insiders preventing outsiders from competing for their jobs. Trade union power could assist the insiders in keeping out the outsiders. Blanchard and Summers (1986) showed that trade unions dominated by insiders could generate a pattern of wage demands that would cause unemployment hysteresis. However, McDonald (1991) shows that this theoretical demonstration can be overturned if union decision-making is assumed to be dominated by a sub-group of members who enjoy secure employment, as might follow from a combination of democratic decision-making and lay-off by seniority.

6. DeLong and Summers (2012, p. 254) cite evidence from Davis and Wachter (2011) which suggests that workers who lose their jobs lose 'an extra amount ... equal to ... a 7.5 percent reduction in permanent earnings'. This loss also raises the question of why wages were not reduced for those who maintained their jobs and thereby enjoyed the benefit of avoiding the income-reducing effect of hysteresis. 
as these may be at times a binding constraint on the outcomes for unemployment and inflation but it does not measure their influence. It does not reveal at what times the lower constraint is binding. Thus, it does not reveal what labour market factors are a binding constraint, nor when they bind and nor where they would bind, that is it lacks information about the potential level of labour market activity.

\subsection{Lubrication}

Schultze (1959) and Tobin (1972) argued that creeping inflation will improve the reallocation of labour in response to heterogenous demand and productivity shocks across firms. They based their argument on the assumption that money wages are sticky downwards. If money wages cannot fall, then firms that experience unfavourable shocks can reduce their relative wage by simply holding their money wages constant while other firms increase their money wages. At low rates of inflation, this mechanism has less force and thus labour market adjustment requires higher unemployment. Building on this idea, Akerlof et al. (1996) constructed a simulation model to show how heterogeneity across firms and downward money-wage rigidity implies a weak influence of unemployment on wage inflation. From this simulation model they show that the long-run Phillips curve will move from being vertical to being negatively sloped for rates of inflation below 3 per cent. Thus, this theory would seem to be an explanation of the deflation puzzle, at least at low rates of inflation.

However, these three papers assume downward money-wage rigidity. They do not give an explanation of why money wages should be downward-rigid. Nor do they present a theory of the lower limit to the rate of unemployment below which their theory of sluggish wage growth would be overcome by an excess demand for labour. For example, in their simulation model, Akerlof et al. (1996, p. 29) base the lower limit on 'the median of existing natural rate estimates' and on their observation that the recent experience of inflation and unemployment supports this median as an equilibrium value.

\subsection{Efficiency wages}

Shapiro and Stiglitz $(1984 ; 1985)$ argue that their efficiency wage model, based on the assumption that it is costly for the employer to monitor the effort of employees, implies a sluggish adjustment of wages. They say 'wage decreases by individual firms would only become attractive as the unemployment pool grows' (Shapiro and Stiglitz 1984, p. 439) and later, in reply to the criticism of Carmichael (1985), 'the efficiency wage theory also provides an explanation of wage dynamics: it explains why one firm may be slow to lower its wages until other firms do so' (Shapiro and Stiglitz 1985, p. 1215). However, their argument does not explain 'ongoing low inflation'; they are simply claiming that their efficiency wage mechanism explains a slow rate of decrease in the rate of inflation. Note also that they do not set out explicitly the dynamic process they have in mind.

\section{THE POTENTIAL CONTRIBUTION OF LOSS AVERSION}

This section shows how incorporating loss aversion into theories of wage determination can provide a microeconomic foundation with the potential to resolve the deflation puzzle. 


\subsection{Theories of trade union bargaining and efficiency wages}

Bhaskar (1990) incorporated loss aversion into wage-bargaining models to explain wage rigidity in the face of high unemployment. He focused on trade unions, continuing from Keynes (1936) and Robinson (1937). However, as indeed Bhaskar (1990) noted, an alternative path of influence of loss aversion to explain wage rigidity is efficiency wage theory. To have a microfoundation which can capture the implications for the deflation puzzle of incorporating loss aversion into both trade union bargaining and efficiency wages, in Appendix 1 we present a simple model that combines wage bargaining with efficiency wages. The model extends a model of Layard et al. (1991, annex 3.1) to incorporate loss aversion both in wage bargaining and in the determination of labour productivity. In this section we describe briefly how this combined trade union/efficiency wage model shows that loss aversion implies a range of unemployment rates within which wage inflation is determined by reference wage inflation. ${ }^{7}$

As shown in Appendix 1, loss aversion implies that in the combined trade union/ efficiency wage model the wage will be determined by the reference wage if the reference wage lies between limits determined by two values, $\left\{k^{+}, k^{-}\right\}$of the mark-up of the wage on the reservation wage. These limits are related to the parameters of the model according to:

$$
\frac{W^{i}}{W^{R E S}}=\left(1-\frac{\phi}{1-\phi} \frac{\left(\beta_{1}+\beta_{2}^{i}\right) \frac{1}{\alpha(1-h)}-1}{1-\frac{\theta^{i}}{\alpha(1-K)}}\right)^{-\frac{1}{\beta_{1}}}=k^{i} \quad \text { for } \quad i=\{+,-\}
$$

where $\{+,-\}$ applies when the wage is greater than or less than the reference wage. Also:

$W=$ money wage;

$W^{R E S}=$ reservation money wage;

$\beta_{1}=$ the worker's elasticity of utility with respect to the wage;

$\beta_{2}^{i}=$ the worker's elasticity of utility with respect to the wage relative to the reference wage;

$\phi=$ union power $=$ the weight of the worker's objective in the bargaining maximand;

$\alpha=$ the elasticity of output with respect to labour input;

$h=$ the reciprocal of the elasticity of the demand for the firm's product with respect to price;

$\theta^{i}=$ the elasticity of the worker's effort with respect to the wage relative to the reference wage; and

$K=$ a constant in the effort function.

To capture loss aversion, assume $0<\beta_{2}^{+}<\beta_{2}^{-}<1$ and $0<\theta^{+}<\theta^{-}<1$. A decrease in the wage below the reference level will reduce utility and productivity by large amounts, given by $\beta^{-}$and $\theta^{-}$respectively, relative to the effects of an increase in wage above the reference level, given by $\beta^{+}<\beta^{-}$and $\theta^{+}<\theta^{-}$. $0<\beta_{2}^{+}<\beta_{2}^{-}<1$ and $0<\theta^{+}<\theta^{-}<1$ implies $k^{-}>k^{+}$and thus a range of wages $\left\{k^{+} W^{R E S}, k^{-} W^{R E S}\right\}$ within which the actual wage is determined by equality with the reference wage.

7. To avoid complexity, we do not include the customer-market influence in this model. A technique for combining trade union wage-setting with seller prices constrained by customer markets is set out in McDonald and Sibly (2005). 
As shown in Appendix 1, using standard assumptions for macro closure, $k^{-}>k^{+}$ implies a range of unemployment rates for which the wage rate is determined by the reference wage. This range is given by:

$$
u^{\min }=\frac{1-\frac{1}{k^{+}}}{1-b} \leq u \leq \frac{1-\frac{1}{k^{-}}}{1-b}=u^{\max },
$$

where $b=$ the unemployment benefit replacement ratio. From (2) both umin and umax are positively related to the unemployment benefit replacement ratio and to the size of the union power parameter. This provides the theoretical basis for including union power and the unemployment benefit replacement ratio in our econometric analysis of the determination of umin.

In summary, for rates of unemployment between umin and umax, wages are determined by reference wages. For rates of unemployment below umin, wages will exceed reference wages and for rates of unemployment above umax wages will fall short of reference wages. Umin and umax are determined by labour supply factors, that is worker power and the unemployment benefit replacement ratio. In the range of equilibria, the actual rate of unemployment is determined by the level of aggregate demand; this makes it a Keynesian model - see McDonald and Sibly (2005) for discussion.

\subsection{The reference wage and the level of activity}

To seek a resolution of the deflation puzzle, loss aversion directs attention to the behaviour of reference wages. In this section we discuss various theories of the determination of reference wages.

\subsubsection{Money illusion and reference wages}

Shafir et al. (1997, pp. 347-348) propose that reference points 'can often be nominal' and find evidence from surveys of opinions to support this with respect to wages. Earlier, Kahneman et al. (1986, p. 731) found from surveys a strong aversion (62 per cent) to a cut in nominal wages, even though a wage cut with the same real wage reduction in an inflationary environment in which money wages actually increased was acceptable for 78 per cent of respondents. There would seem to be something special about cuts in nominal wages, for given real wage outcomes. Palley (1990) has a valuable discussion of theorising about downward nominal wage rigidity. ${ }^{8}$

The special importance of aversion to reductions in nominal wages rather than real wages suggests modelling the reference wage as the current nominal wage. This implies that the downward impact on wage inflation of unemployment will be weaker at low rates of inflation. And not just at zero inflation. As noted above, the lubrication theory shows that heterogeneity of firms implies a weak influence of unemployment on wage inflation at low positive rates of inflation; up to 3 per cent inflation according

8. However, note that Kahneman et al. (1986, p. 733) found that cuts in money wages are acceptable if firms are making losses - an example of their dual-entitlement model. Benigno and Fornaro (2015) present a list of references that suggest the existence of money-wage rigidities. Holden and Wulfsberg (2009) find stronger evidence for downward money-wage rigidity than downward real-wage rigidity. 
to the simulations in Akerlof et al. (1996). Specifying the reference wage as the existing money wage would provide a prospect theory base to the lubrication theory.

\subsubsection{Passive approaches}

Bhaskar (1990), following Keynes (1936), assumed the reference money wage is the money wage expected to be received by other workers. As noted above, under this assumption, in macroeconomic equilibrium any wage in the range defined above by (2) is a perfect-foresight equilibrium. ${ }^{9}$ This specification of reference-wage determination resolves the deflation puzzle for rates of unemployment lying between umin and umax. That is, if workers expect the wages of other workers to be increasing then their reference money wage will be increasing and so their money wage demands will be increasing, independently of the rate of unemployment (provided of course that unemployment remains within the limits of umin and umax).

For $u<$ umin the wage that maximises the wage bargain will exceed the reference wage. If actual wages are set accordingly they will exceed the expected wage. Then it is reasonable to suppose that wage expectations and thus the reference wage will be revised up in line with actual wages and this will lead to bargained wages adjusting upwards to maintain their excess over reference wages. This would tend to put upward pressure on wage inflation. However, the intensity of that pressure, and so whether wage rates would be accelerating, can be linked to whether, in Robinson's (1937, p. 15) words, 'employers themselves throw their weight into the scale of rising wages'. If trade union bargaining dominates then employers would be resistant to wage increases: they would not throw their weight into the scale of rising wages and so acceleration would be weak or even non-existent. But if the efficiency wage mechanism dominates, then it is in the interest of employers to be pushing up wages in their search for optimal efficiency and given that employees are not against wage increases, the upward pressure would be greater.

For $u>$ umax, bargained wages would fall short of reference wages. The logic above for $u<$ umin would apply in reverse, although perhaps with less intensity because the employed may be slow to adjust down their reference wages. Given the dislike by employees of reduced wages, self-serving bias may induce them to underestimate the facts of wages below reference levels.

\subsubsection{Active approaches}

Bhaskar's, and Keynes's, approach to expectations formation can be described as passive. It is a bootstrap theory of inflation where unions simply follow other unions. A more active theory of reference wage-setting can be derived from Robinson's (1937, p. 4) suggestion that unions 'demand a rise and resist a cut [in money wages] whenever they feel strong enough to do so'. McDonald (2019) calls this Robinson's proactive postulate and sets Robinson's view within prospect theory. Thus, the trade union is modelled as actively setting a reference money wage when it seeks to take advantage of an improvement in its position. By inducing its members to code a wage claim as the reference money wage, the union will strengthen the support that workers will give to achieving the money-wage claim because if they fail then they will suffer loss aversion. This threat will strengthen their determination and cohesion.

9. This is consistent with the rational expectations approach to reference level determination of Koszegi and Rabin (2006). 
Robinson's proactive postulate provides a stronger basis to resolve the deflation puzzle than the passive approach to reference-wage determination. Under the passive approach, any success by employers in preventing wages from increasing by the full amount of reference wages will get transferred over time into the reference wage and thus into actual wages, going forward. The passive approach has no role for union power to directly affect wages. By contrast, Robinson's proactive postulate implies that unions will increase money wages when they perceive an increase in nominal labour demand at the microeconomic level, independently of the wages of other workers. If unions are powerful enough, they can ensure that money wages increase with the value of their marginal product, thereby ensuring that nominal unit-labour costs (ULCs) increase with the rate of price inflation. Any falling behind in wages will be offset during subsequent periods, rather than being factored in during subsequent periods. Furthermore, improvements in labour productivity would also be transferred to increases in money wages if unions are strong enough to follow Robinson's proactive postulate.

Speed limits, that is a change in activity such as a reduction in the rate of unemployment driving a change in wages, is a common finding in the empirical literature - see for example Phillips (1958), Gordon (1990; 1997; 1998; 2018), Romer (1996) and Gruen et al. (1999). ${ }^{10}$ Robinson's proactive postulate can be an explanation of the speed limit effect because it implies that an increase in nominal labour demand above trend may lead to similar-sized increases in wages if unions are powerful enough.

Positing unions to be active in their setting of the reference wage suggests that a change in union power can have a direct effect on wage outcomes even if the rate of unemployment is within the range of equilibria. Under passive approaches, a change in the degree of union power changes umin and umax but has no effect on wages if unemployment remains within the range of equilibria.

Wages have fallen sharply and temporarily on occasion, such as in the early 1930s. A reconciliation of this downward speed limit lies in how firms and their workers react to the threat of profits being replaced by losses. That is, a severe contraction in product demand may push some firms into extreme financial duress, in which case workers may accept wage reductions to prevent mass lay-offs - see for example Akerlof et al. (1996), Bewley (1999) and, for a theoretical account in the loss-aversion model, see McDonald (2019).

Finally, under the active approach a downward trend in union power can cause a downward trend in wage outcomes.

\subsubsection{Employer influences on reference wages}

The efficiency wage model has employers setting the wage. To avoid low efficiency employers would be conscious of the reference wage held in the minds of workers and these reference wages may be influenced by the actual wage or the wages of other workers, as in passive approaches, or by the perceived capacity to pay of the employers, as in the active approaches. Shafir et al. (1997) present an efficiency wage model in which workers' effort is positively related to the increase in nominal wages at a given real wage. They also suggest (ibid., fn 22) that a longer history of past inflation may be the driving force in the effort function. This is an example of the passive approach.

10. Gordon places a lot of emphasis on the importance of speed limits, which is one of three vertices in his triangle model of inflation. Robinson (1937, p. 7) observed that 'movements of the level of employment are the chief influence determining movements in the level of money wages'. 
As with the trade union bargaining approach, in a state of high unemployment and thus a ready availability of outsiders, efficiency wages with passive reference wage-setting may enable employers to chip away at the growth of the nominal wage and thereby, in as far as reference wages follow actual wages, reduce the growth of the reference nominal wage. And again, this possibility suggests a certain fragility to the ability of prospect theory to resolve the deflation puzzle.

\subsubsection{Reference wages in our empirical specification}

The passive approach to reference-wage formation suggests that wages move with expected inflation and so we specify our estimating equation for inflation such that the coefficient on expected inflation is equal to one. To capture the possible influence of the active approaches to reference-wage formation we include speed limits in the form of the change in the rate of unemployment and also allow for a direct effect on wages of changes in union power.

\section{ESTIMATES OF THE LOSS-AVERSION MODEL}

\subsection{The estimating model}

To estimate the range model, we use a two-regime specification of the estimating model as in Lye et al. (2001).

We use the following variables:

$U L C=(\log )$ unit-labour costs;

$P=(\log )$ consumer price level;

$P^{*}=(\log )$ expected price level based on forward-looking survey data;

$u=$ rate of unemployment; and

$r_{i}=$ labour supply factors.

In our specification, we allow the coefficients of the short-run Phillips curves (SRPCs) to take different values within two regimes which we will call from now on low- and high-unemployment regimes. ${ }^{11}$ The behaviour of inflation across the two regimes behaves according to the following estimating equations.

$$
\Delta_{4} \ln U L C_{t}-\Delta \ln P_{t-1}=\pi_{t}^{P} X_{t}^{P}+\left(1-\pi_{t}^{P}\right) X_{t}^{R},
$$

with the within-regime behaviour described by

$$
\begin{aligned}
& X_{t}^{i}=a_{1}^{i}\left(\Delta_{4} \ln P_{t}^{*}-\Delta_{4} \ln P_{t-1}\right)+a_{2}^{i}\left(u_{t}-u_{t}^{\min }\right)+a_{3}^{i}\left(u_{t-1}-u_{t-2}\right) \\
& +a_{4}^{i}\left(\Delta_{4} \ln U L C_{t-1}-\Delta_{4} \ln P_{t-2}\right)+a_{5}^{i}\left(\Delta_{4} \ln U L C_{t-1}-\Delta_{4} \ln U L C_{t-4}\right)+v_{t}^{i},
\end{aligned}
$$

for $i=$ low unemployment, high unemployment. $\Delta_{4} X_{t}=100 *\left(X_{t}-X_{t-4}\right)$, which approximates percentage change. $u_{t}^{\min }$, the rate of unemployment between the low- and high-unemployment regimes, is related to supply-side factors, $r_{i, t}$, by

$$
u_{t}^{\min }=\alpha_{0}+\sum_{i} \alpha_{i} r_{i, t} .
$$

11. The two-regime specification. 
In (3) the use in the dependent variable of the change in real ULCs (= change in nominal wages per employee divided by output per employee minus the change in the CPI) as the measure of wage inflation follows Gruen et al. (1999) and Lye et al. (2001). In our behavioural context, the difference between $\Delta_{4} \ln U L C_{t}$ and $\Delta_{4} \ln P_{t-1}$ can be interpreted as a measure of the sharing of the gains from rising total factor productivity between labour and capital. For example, the benchmark value of $\Delta_{4} \ln U L C_{t}-\Delta_{4} \ln P_{t-1}=0$ implies, ignoring changes in the terms of trade, that real wages have kept up fully with the rise in labour productivity. ${ }^{12}$

(4) is based on an accelerationist specification in which the expected rate of inflation appears on the right-hand side with a coefficient of one. That is:

$$
\Delta_{4} \ln U L C_{t}=\Delta_{4} \ln P_{t}^{e}+\text { other variables. }
$$

Defining the expected consumer price level by a mixture of forward- and backwardlooking components according to $\Delta_{4} \ln P_{t}^{e}=a_{1}^{i} \Delta_{4} P_{t}^{*}+\left(1-a_{1}^{i}\right) \Delta_{4} \ln P_{t-1}$ gives (4).

$\Delta_{4} \ln U L C_{t-1}-\Delta_{4} \ln P_{t-2}$ is the lagged dependent variable. $\Delta_{4} \ln U L C_{t-1}-$ $\Delta_{4} \ln U L C_{t-4}$ captures differences in the behaviour of inflation at quarterly and annual frequencies, see Gruen et al. (1999).

Equation (3) determines the relative importance of the two inflation equations in (4) according to the continuous dummy variable $\pi_{t}^{P}$. This variable is specified to depend on $u_{t}, u_{t}^{\min }$ and the transition parameter, $\gamma$, according to the logistic equation:

$$
\pi_{t}^{P}=1-\frac{1}{1+\exp \left[-\gamma\left(u_{t}-u_{t}^{\min }\right)\right]},
$$

where the value of $\gamma$ determines the transition from the low- and high-unemployment regimes, with higher values giving a faster transition. To determine $u_{t}^{\min }$ we specify the relation (5) and estimate the parameters.

Maximum likelihood is used to estimate (3) assuming independent, normally distributed random errors $\nu_{t}^{i}$ with mean 0 and variances $\sigma_{i}^{2}$ for $i=$ low unemployment, high unemployment. Sources and descriptive statistics of the data used in the estimation process are given in Appendix 2 along with figures showing the pattern of inflation in both countries.

\subsection{The estimates}

In this section we discuss our estimates of the inflation-unemployment relation. First, we discuss how trade union power may influence wage outcomes while the economy is within the high-unemployment regime. Then we discuss the implications of our estimates for the determination of umin, the shape of the short-run Phillips curve and the dynamics of inflation. Following that, we compare the estimates with estimates using the natural rate of unemployment specification and with the estimates of BCS's hysteresis specification.

\subsubsection{Union power and our preferred specification of the estimating equation}

Our preferred form for the inflation equation allows for changes in union power to have a direct effect on wage outcomes. As discussed above, in the range theory,

12. Gruen et al. (1999, p. 234) argued for ULCs on the basis that ULCs are more relevant for pricing decisions, which were a part of their two-equation model of wages and prices. 
this possibility exists with active approaches to reference wage-setting. In Table 1, columns 1 and 2 for the US and 5 and 6 for Australia report estimates for this specification in which a variable for the change in union power is included in the list of variables in $X_{t}^{\text {range }}$ in (4).

Having used union density as an explanatory variable in the umin equation, we considered alternative measures of union power. One variable that stands out is the share of manufacturing employment in total employment. As Figure 1 shows, this variable is corelated with union density for both the US and Australia, more highly for the US.

For comparative purposes, columns 3 and 4 for the US and 7 and 8 for Australia update the estimates of the specification of the two-regime, loss-aversion model we used in Lye et al. (2001) in which union power was not allowed to have a direct effect on wages.

Columns 1 and 2 in Table 1 show that for the US the estimated coefficient on the percentage change in the manufacturing employment share is of the right sign in the high-unemployment regime and marginally significant, with a $p$-value of 0.08 . For Australia the coefficient has the right sign but is insignificant. Notwithstanding the insignificance of the estimated coefficient for Australia, we prefer the specification that includes the percentage change in the manufacturing employment share because the estimated coefficient on union density in the umin equation is more precisely estimated, with a $p$-value of 0.00 compared with 0.29 when the manufacturing employment share is not included. The greater precision of the estimated coefficients is reflected in the greater precision of the implied estimates of umin over the estimation period. The average size of the 95 per cent confidence interval on umin is reduced from 1.47 percentage points to 0.75 percentage points, as reported in the bottom row of columns 6 and 8 in Table 1. Furthermore, the residuals without the percentage change in the manufacturing employment share have a mild negative trend, suggesting specification error. This trend is removed when the manufacturing employment share is included. So, in what follows for both economies we focus on the estimated specification with the percentage change in the manufacturing employment share included, that is the estimates in columns 1,2, 5 and 6 of Table 1 .

\subsubsection{The patterns of umin}

For both economies, our estimates of the umin equation show that the supply factors have a significant influence on umin. As reported in Table 1, the estimates of the coefficients on the unemployment benefit replacement ratio and union density are significant with $p$-values of 0.00 and with the correct signs. In addition, for the US the demographic variables are significant. The average size of the 95 per cent confidence interval on umin for both economies is small. It will be seen below that the implied estimates of umin are more precisely determined for both economies compared with estimates of the natural rate model.

The patterns of umin along with the 95 per cent confidence intervals for both economies are shown in Figures 2 and 3. For the US, little time has been spent in the low-unemployment regime, indeed only 12 quarters out of the 231 quarters in the estimation period. That is a mere 5 per cent of the time. Australia, on the other hand, spent 31 per cent of the estimation period in the low-unemployment regime. That was mainly in the earlier part of the estimation period.

In each of the US and Australia there were occasions of substantial changes in umin related to substantial changes in the unemployment benefit replacement 


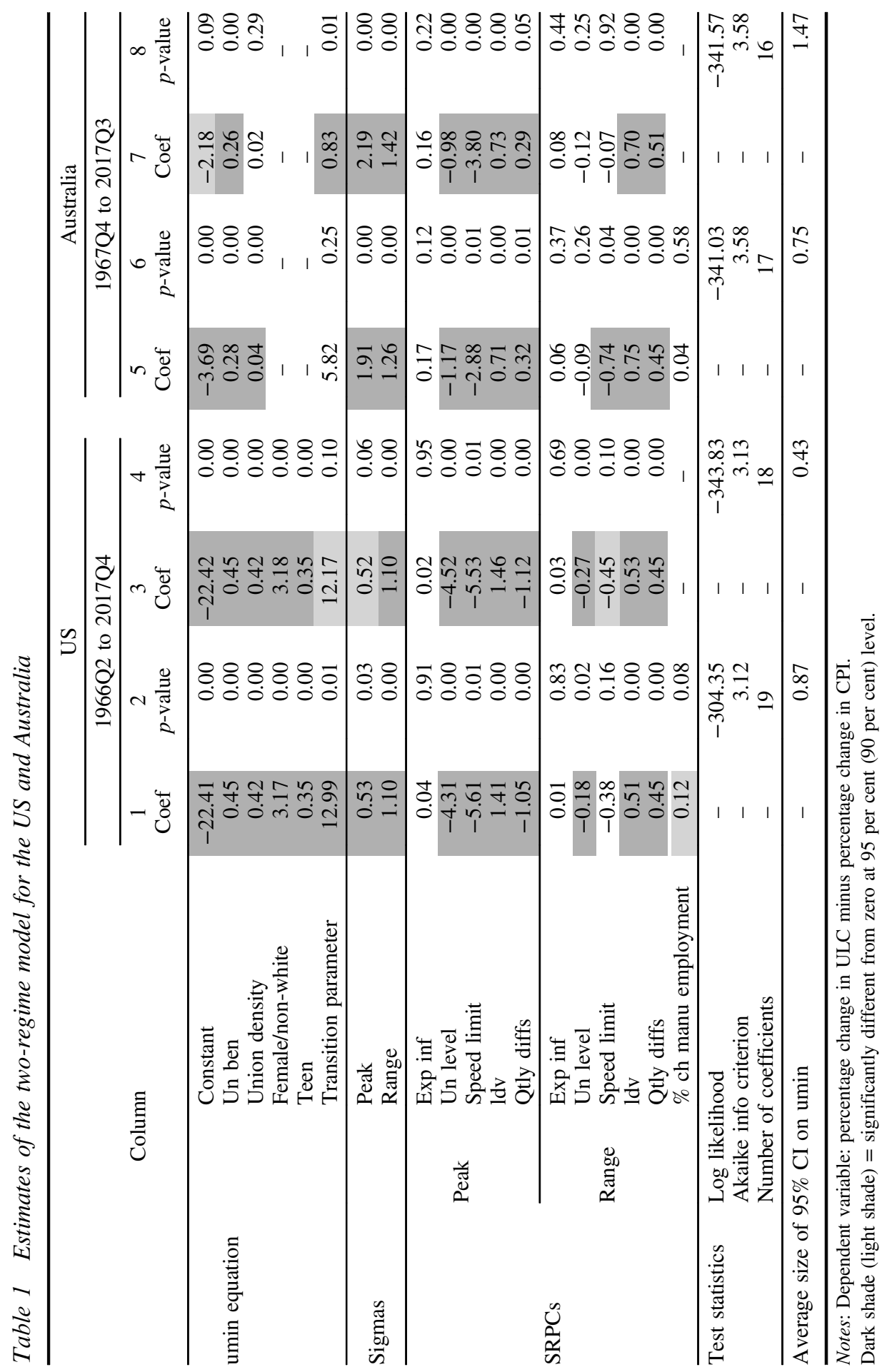


ratio; see Figures 1, 2 and 3. For the US during the period 2008 to 2012 the replacement ratio increased temporarily by roughly 10 percentage points through extending the period of eligibility for unemployment benefit payments. This was a policy response designed to protect unemployed people from the ravages of the global financial crisis see Marinescu (2017). This extension in duration is picked up by the OECD measure of the unemployment benefit replacement ratio. In response, umin increased substantially, by roughly 4 percentage points, that is doubling.

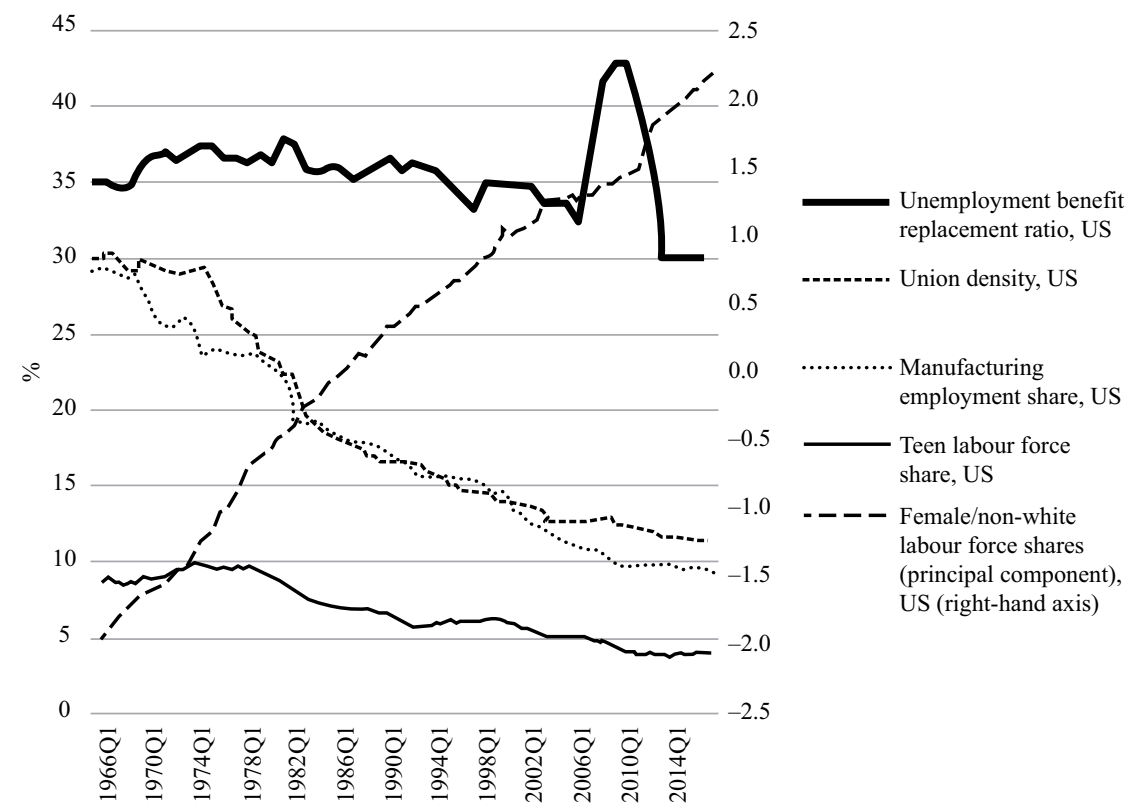

US, 1966Q1 to 2017Q4

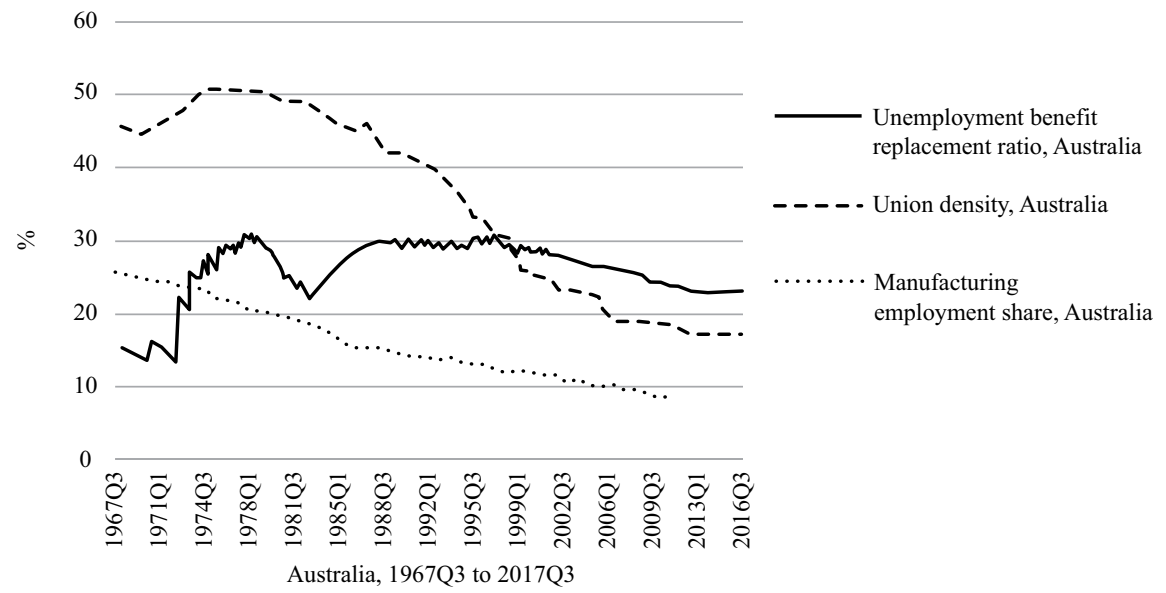

Figure 1 Supply-side factors 


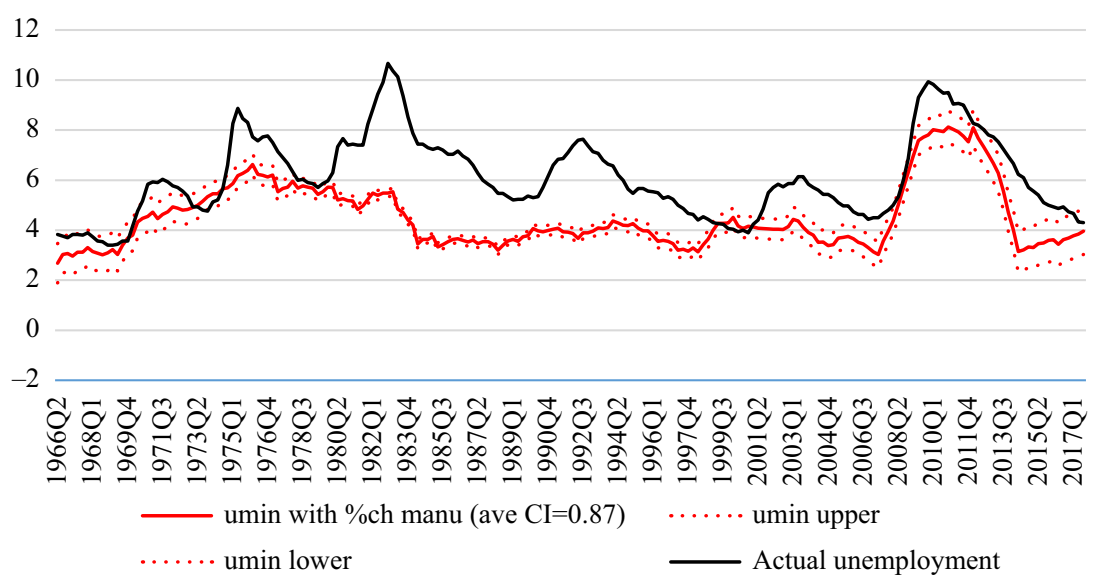

Figure 2 umin with confidence limits, US, $1966 Q 2$ to $2017 Q 3$

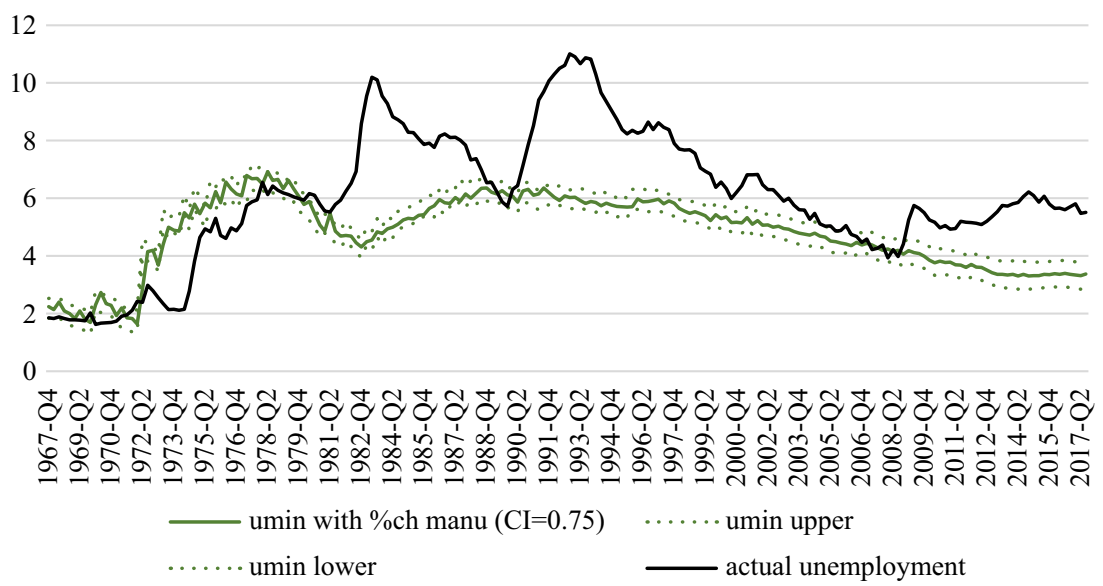

Figure 3 umin with confidence limits, Australia, 1967Q4 to 2017Q3

It has been argued that the effect of the increase in the generosity of the US unemployment programme increased actual unemployment over this period - see for example Barro (2010). However, our estimates cast doubt on this inference because actual unemployment increased by more than umin. Thus, in this period supply-side factors did not drive the actual rate of unemployment and, given the small size of the unemployment-level effect in the range, did not put upward pressure on inflation.

For Australia there was a substantial increase in unemployment benefits over the period 1972Q1 to 1973Q1 of about 14 percentage points. This was partly intended as a demand stimulus to cope with an increase in unemployment and partly to realign 
the unemployment benefit payment with the old age pension payment, which had been increased earlier. Our estimates show that demand stimulus was inappropriate at the time because umin was slightly greater than the actual rate of unemployment in 1971Q4: 2.12 compared with 1.75. The increase in the unemployment benefits pushed umin way above the actual rate of unemployment, thereby inducing an inflationary situation.

Thus these two episodes of substantial change in help to the unemployed are a contrast. The US response in 2008 to 2012 is a case of redistribution without causing inflationary pressure. On the other hand, the Australian policy change in 1972 does seem to have contributed to inflationary pressures. This contrast underlines the fact that in the range model, and in Keynesian economics, actual outcomes can diverge from potential outcomes. In the classical/natural rate model, actual outcomes are closely tied to potential outcomes.

Bearing in mind that the patterns of umin and umax are determined by the patterns of the supply factors, there is an interesting similarity between Australia and the US. For both economies, the supply factors pushed up umin and umax to a maximum in the late 1970s, by roughly 4 percentage points in both economies, and then tended to push umin down over the next 40 years to the end of the sample period. At the end of the data period, umin was at similar levels to those of the 1960s: at 4.0 per cent and 3.3 per cent for the US and Australia respectively, that is for 2017Q4 and 2017Q3.

We suggest that the movement of supply factors played a major part in the surge in inflation in the late 1960s to early 1970s. Policy-makers, being either unaware of this influence or aware but unable to respond effectively, struggled to keep up with the worsening possibilities for unemployment. Thereby this lack of knowledge about umin caused the surge in inflation. Subsequently, the downward stickiness of inflation when unemployment was within the high-unemployment regime impaired the appreciation by policy-makers of the improvement in possibilities for reducing unemployment due to the change in the supply factors. ${ }^{13}$

\subsubsection{The short-run Phillips curves (SRPCs)}

The SRPC is the relation between inflation and unemployment holding expected inflation constant and assuming no influence of changes in unemployment and inflation. Thus, the SRPC highlights the influence of the unemployment-level effects. For the two-regime model the SRPC is derived from (3) and (4) with $u_{t-1}=u_{t-2}$, $\Delta_{4} \ln U L C_{t-1}=\Delta_{4} \ln P_{t-2}$ and $\Delta_{4} \ln U L C_{t-1}=\Delta_{4} \ln U L C_{t-4}$. This gives the SRPC as:

$$
\begin{aligned}
& \Delta_{4} \ln U L C=\Delta_{4} \ln P^{e}+a_{2}^{P}\left(u-u^{\min }\right) \text { for } 0 \leq u \leq u^{\min } \\
& \Delta_{4} \ln U L C=\Delta_{4} \ln P^{e}+a_{2}^{R}\left(u-u^{\min }\right) \text { for } u>u^{\min } .
\end{aligned}
$$

The SRPCs for Australia and the US are plotted in Figure 4, assuming the expected rate of inflation $=2.5$ per cent and umin $=4$ per cent.

The pronounced kink on the SRPCs at unemployment equal to umin for both economies, sharper for the US, see Figure 4, shows the substantially larger estimates of the unemployment-level effect in the low-unemployment regime compared with the high-unemployment regime; that is, -4.31 compared with -0.18 for the US and -1.07

13. Was there some common global force on the supply factors causing them to increase in the 1970s?. 


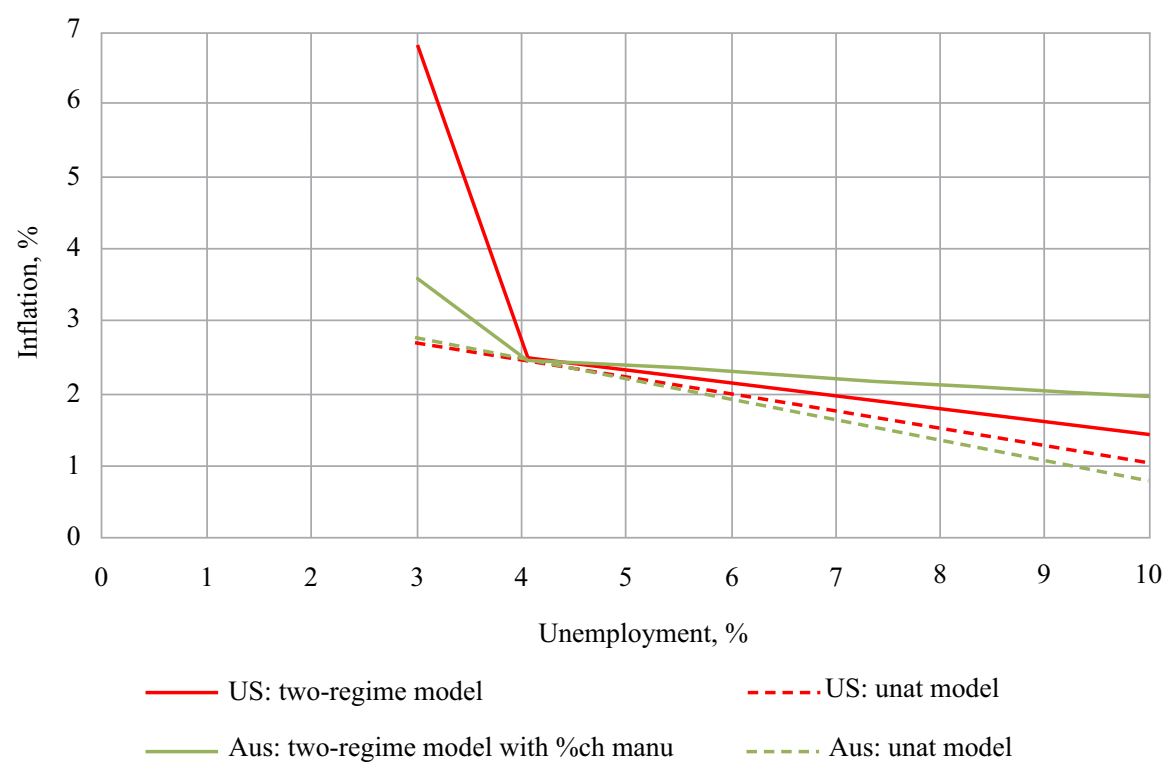

Figure $4 \quad$ SRPCs, setting umin/unat $=4$ per cent

compared with -0.09 for Australia. The sharpness of the kink is partly determined by the high estimate of the transition parameter. ${ }^{14}$

The greater sensitivity of inflation to unemployment at low compared with high rates is not only reflected in the steeper SRPCs at low unemployment. The speed limit effect is also greater in the low-unemployment regime than at high unemployment. Indeed, the speed limit coefficient for both economies is large and highly significant in the low-unemployment regime and relatively small, and insignificant for the US, in the high-unemployment regime.

\subsubsection{Deceleration}

The very weak deflation effect of high unemployment suggests that the forces of deceleration at high unemployment rates would be small. Supporting this inference, there is no evidence to suggest that in either the US or the Australian economies the rate of ULC deflation was decreasing as time spent in the regime of high rates of unemployment increased.

Figure 5 shows the rate of nominal ULC inflation for the US during the four sequences of quarters when the US economy was in the high-unemployment regime. For none of these sequences does ULC inflation tend to decrease as time spent in the high-unemployment regime increases. The deceleration logic does not show up even

14. The estimated value of the transition parameter $(\gamma=12.99)$ for the US implies that the regime dummy goes from 0.8 to 0.2 over an interval of 0.2 percentage points of unemployment. For Australia, $\gamma=5.82$ implies that the regime dummy goes from 0.8 to 0.2 over an interval of 0.5 percentage points of unemployment. For Australia without the manufacturing variable the estimated transition parameter is $\gamma=0.83$, which increases this measure of the size of transition to 3.4 percentage points of unemployment, implying a much smoother transition. 


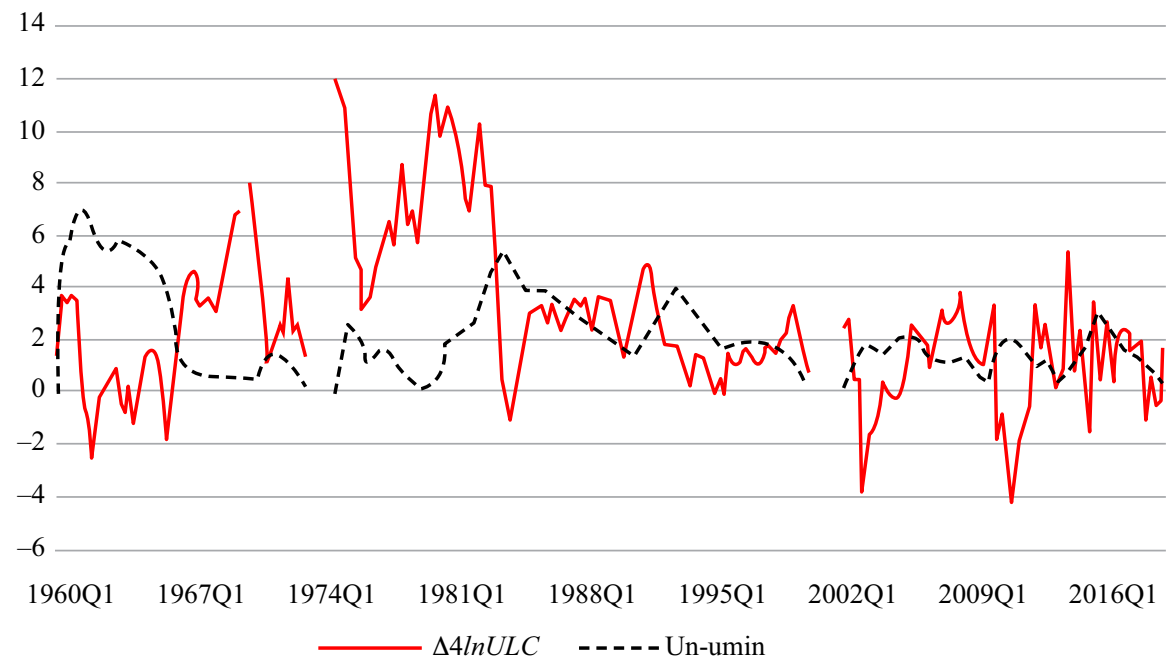

Figure 5 Nominal ULC inflation for unbroken sequences of quarters within the highunemployment regime, US

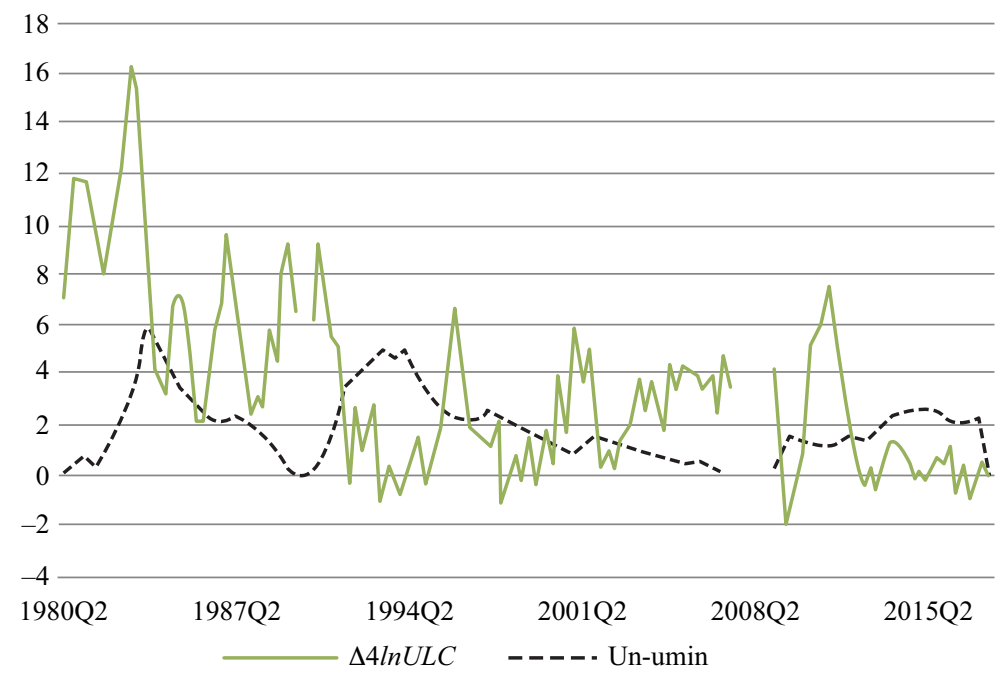

Figure 6 Nominal ULC inflation for unbroken sequences of quarters within the highunemployment regime, Australia

when the time spent in the high-unemployment regime is considerable: that is, the 100 quarters from 1974Q3 to 1999Q2.

For Australia, it is a similar story: the unbroken sequences within the high-unemployment regime show no evidence of deceleration; see Figure 6. This supports the inference that the insignificant estimate of the unemployment-level effect in the high-unemployment regime implies no deceleration of inflation while in that regime. 


\subsubsection{Acceleration}

For the five consecutive quarters when the US economy was in the low-unemployment regime, from 1973Q2 to 1974Q2, nominal ULC inflation was increasing, in line with the acceleration hypothesis; see Figure 7. The increase in ULC inflation was quite substantial, being about 7 percentage points of inflation over five quarters. Note also that during this sequence, actual unemployment was not far below umin. So, a small amount of excess demand caused substantial acceleration of wage inflation.

However, for the US for the six consecutive quarters 1999Q3 to 2000Q4 in the lowunemployment regime, during which the gap between actual unemployment and umin was similar in size to the earlier period in the low-unemployment regime, ULC inflation shows a rather muted increase, suggesting a lack of acceleration dynamics; see Figure 7.

For Australia, there seems to be evidence of acceleration in the early period of an unbroken sequence of quarters within the low-unemployment regime, that is for the 14 quarters 1967Q4 to 1971Q3; see Figure 8. However, the later sequence of 30 quarters within the low-unemployment regime, 1972Q2 to 1979Q3, shows a more complicated history. The suggestion of acceleration in the first part of this sequence ends abruptly in 1974Q4 and is followed by a reduction in wage inflation. This abrupt cessation of acceleration reflects the substantial reduction in the size of the gap between unemployment and inflation immediately following 1974Q2. From 1974Q2 to 1975Q2 the un-umin gap fell from -3.6 to -0.41 percentage points. This an example of the speed limit effect. Note that the coefficient on the speed limit for Australia when in the low-unemployment regime is substantial and significant; see Table 1.

Following 1975Q2, ULC inflation decreases even though the un-umin gap remained negative for the remaining five years of this sequence of quarters in the low-unemployment regime. This was a period of substantial interaction between the Arbitration Commission, a centralised wage-fixing body, and trade unions,

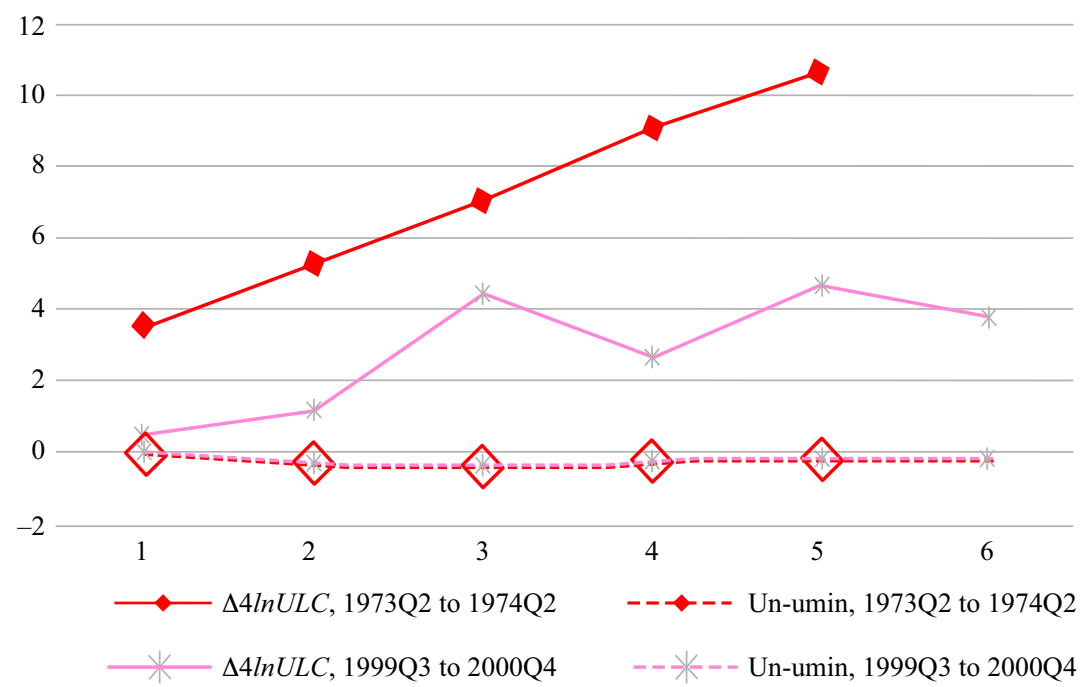

Figure 7 Nominal ULC inflation and un-umin for unbroken sequences of quarters within the low-unemployment regime, US 


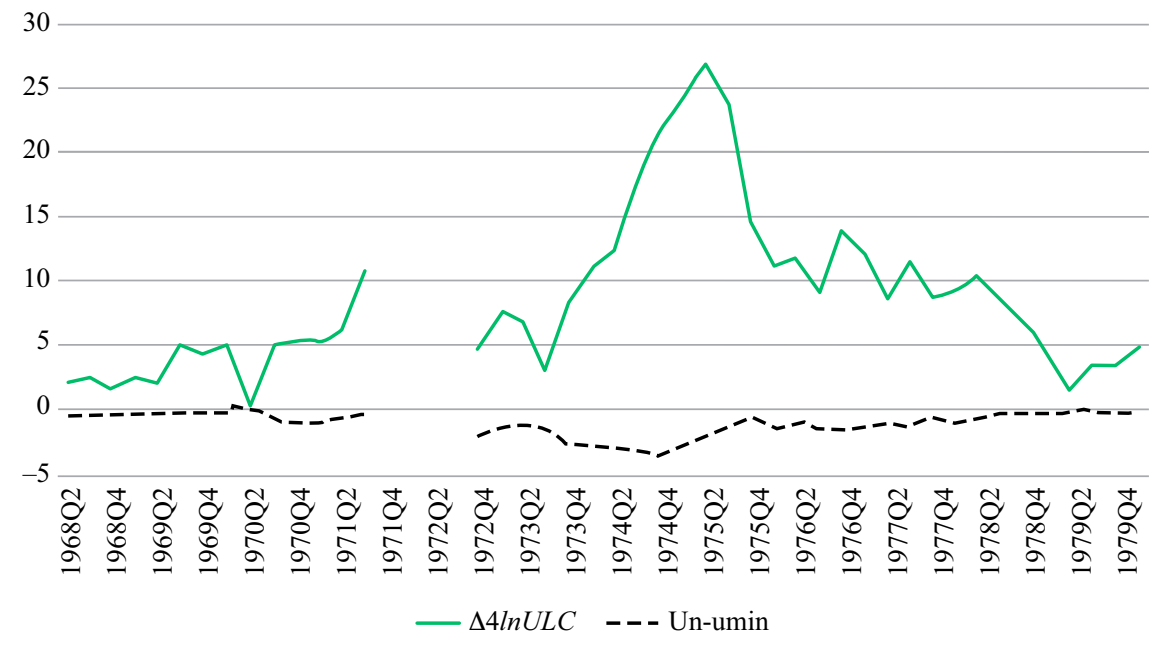

Figure 8 ULC inflation and un-umin for unbroken sequences of quarters within the peak, Australia

aimed at controlling the rate of wage inflation, including notably the introduction of wage indexation in 1975. Our exploration using the two-regime model in Lye and McDonald (2006) finds statistical support, albeit weak, for the effectiveness of this interaction in controlling inflation.

In summary, for both economies the evidence for low unemployment relative to umin causing increasing inflation is mixed, being strong before the mid 1970s and muted after. Indeed, for Australia, our estimates suggest that the period of low unemployment from 1972Q2 to 1979Q3 was not one of excess demand but of a battle between unions and employers with the latter aiming to keep wages down rather than increase wages to cope with labour shortages.

\subsubsection{The natural rate model}

The natural rate (unat) model assumes one regime with a single value for the unemployment-level effect. Estimates assuming just one regime are reported in Table 2. For both the US and Australia, these estimates show how the one-regime model fails to pick up the high sensitivity of inflation to unemployment at low rates of unemployment. Thus, the unemployment-level effects in the unat model are -0.24 and -0.28 for US and Australia respectively, compared with, for the two-regime model, -4.31 and -1.17 for the low-unemployment regimes; see Table 1 .

The influence of supply factors on unat is somewhat similar to their influence on umin. However, the average size of the 95 per cent confidence interval on unat is considerably wider than on umin, being 8.41 and 6.13 percentage points of unemployment compared with 0.87 and 0.75 for umin. ${ }^{15}$

15. Including the percentage change in the manufacturing employment share reduces the precision of the unat estimates by a large amount, in contrast to the effect on umin in the two-regime model. 


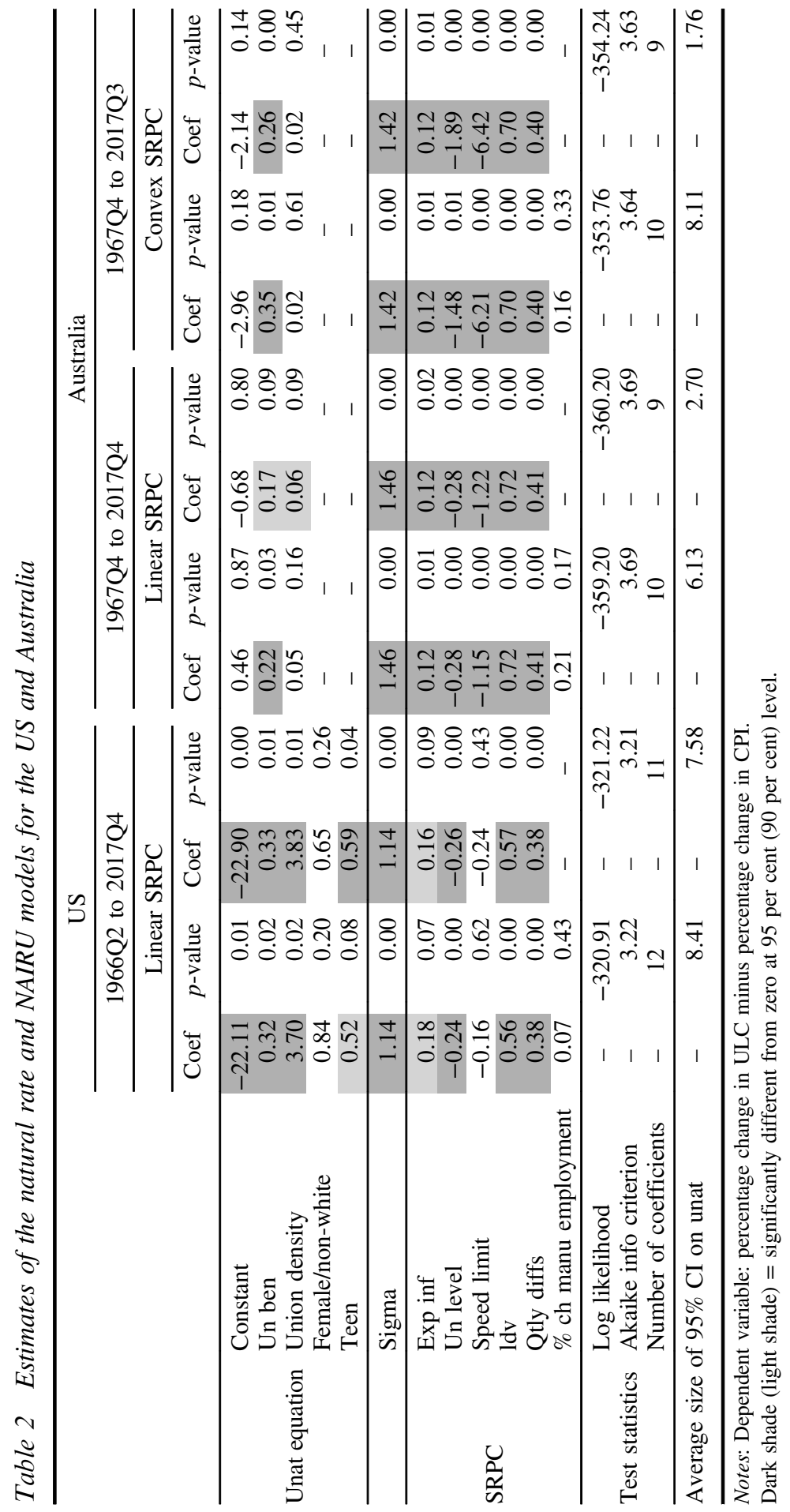


Expected inflation, as measured by surveys of opinion, has very little influence in either the two-regime model or the natural rate model. The coefficient on expected inflation is small, being 0.18 for the US and even smaller, 0.12, for Australia. Given our specification, this implies lagged inflation dominates the expectations story.

For Australia we also report estimates with a convex SRPC, specified as:

$$
\begin{aligned}
& X^{t}=a_{1}\left(\Delta_{4} \ln P_{t}^{*}-\Delta_{4} \ln P_{t-1}\right)+a_{2}\left(\frac{u_{t}-u_{t}^{\min }}{u_{t}}\right)+a_{3}\left(\frac{u_{t-1}-u_{t-2}}{u_{t}}\right) \\
& +a_{4}\left(\Delta_{4} \ln U L C_{t-1}-\Delta \ln P_{t-2}\right)+a_{5}\left(\Delta_{4} \ln U L C_{t-1}-\Delta_{4} \ln U L C_{t-4}\right)+v_{t} .
\end{aligned}
$$

This is a prominent form in Australia - see especially Gruen et al. (1999) - and follows the original specification of Phillips (1958). As in Gruen et al. (1999), the speed limit is also specified in convex form.

The estimates with a convex SRPC show less-precise estimates of NAIRU compared with the estimates of umin. The average size of the 95 per cent confidence interval on NAIRU is 8.11 percentage points of unemployment compared with 0.75 percentage points for umin. However, the NAIRU is more precisely estimated when the percentage change in the manufacturing employment share is excluded, being reduced to 1.76 percentage points of unemployment.

\subsubsection{BCS hysteresis}

Figures 9 and 10 compare the umin estimates with the BCS estimates of their hysteresis NAIRU for the US and Australia. ${ }^{16}$ The degree of precision of the BCS NAIRUs is lower than for umin: the average size of the 95 per cent confidence interval for the US is 1.65 compared with 0.87 and 1.06 compared with 0.75 for Australia.

The striking contrast between umin and the BCS NAIRU is the relative smoothness of the latter. This presumably is a result of the a-theoretical approach of the time-varying approach used for the BCS NAIRU. Even so, using the knowledge created by the umin estimates, one can discern from the pattern of the BCS NAIRU a muted and somewhat lagged influence of labour supply factors. Thus, for the US, the substantial increase in umin up to 1976, reflecting the labour supply factors, is echoed in an accompanying gradual and slight increase in the BCS NAIRU. After 1976, when the labour supply factors were pushing umin down, the BCS NAIRU continued to increase, peaking in 1983. Given the downward influence of supply-side effects suggested by the direction of umin, the continuing increase in the BCS NAIRU presumably reflected the increase in actual unemployment during this period.

For Australia, one can also discern a muted and lagged response of the BCS NAIRU to umin. The mute is strong enough for the BCS NAIRU to completely miss the supply-side dip in potential activity in the period 1977Q4 to 1988Q1.

Generally, for the US, the BCS NAIRU is well above umin, with the exception of the temporary bump during the Great Recession. This demonstrates the point made above that the hysteresis model as specified does not define a lower limit to the unemployment rate consistent with hysteresis and so gives little guidance to policy-makers on the potential level of activity.

16. The sample period for BCS is 1961Q2 to 2014Q4. 


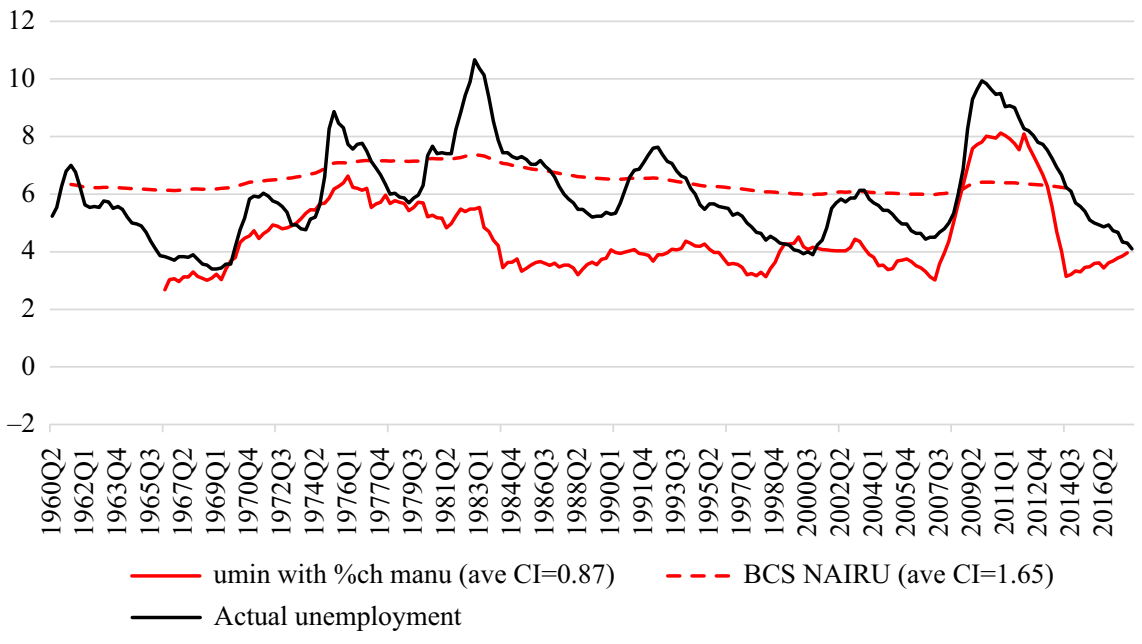

Figure 9 umin and the BCS hysteresis NAIRU, US, 1960Q2 to 2017Q4

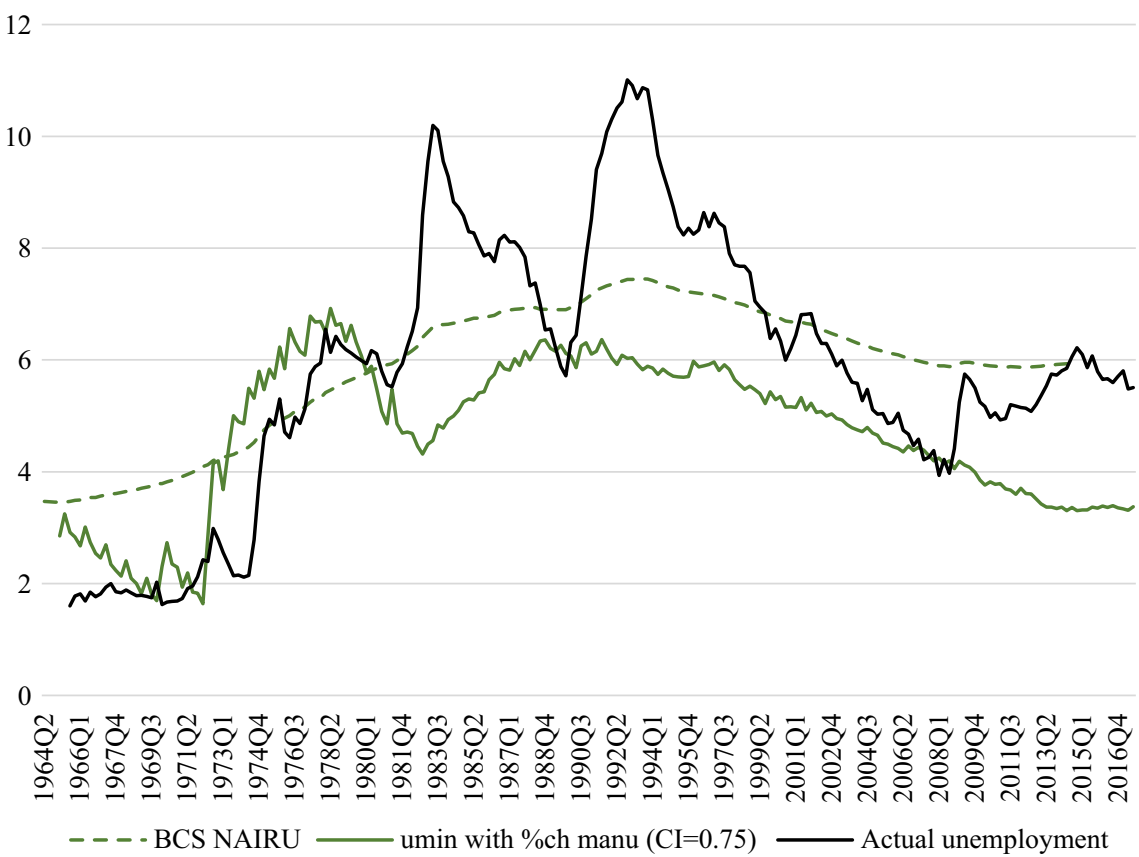

Figure 10 umin and the BCS hysteresis NAIRU, Australia, 1964Q2 to $2017 Q 3$

\section{CONCLUSION}

The estimates of the relationship between real unit-labour cost (ULC) inflation and unemployment reported in this paper suggest that loss aversion by workers with 
respect to wages offers a resolution to the deflation puzzle. The loss-aversion approach implies a resistance to reductions in the rate of money-wage inflation. This resistance implies a very flat short-run Phillips curve (SRPC) at rates of unemployment above a supply-side determined level that we call umin. Our estimates for the US and Australia find this. For the US, the SRPC has a negative slope for unemployment rates above umin, but this slope is very small. For Australia, the slope of the SRPC for unemployment rates above umin is flat, and so at high unemployment there is no statistically significant force to cause inflation to decelerate. Instead, high unemployment is consistent with ongoing low inflation.

In fact, for both economies during the sequences of quarters of high unemployment, we find no evidence of deceleration of ULCs. Thus, even the slight negative slope of the SRPC for the US was not enough to lead to deceleration. This is not surprising. The slight negative slope for the US implies that an increase of 1 percentage point in unemployment would decrease the rate of inflation by 0.18 percentage points. Such a decrease would be hardly noticeable and so provides a very weak statistical counterargument to our conclusion that loss aversion can explain the deflation puzzle.

Theoretically, the dynamics of wage inflation implied by the loss-aversion approach to wage determination suggests a muted deceleration effect even if high unemployment can cause a slight downward effect on wage inflation, as estimated for the US. With loss aversion the supply price of labour is determined by the reference wage and so the downward dynamic depends upon the downward adjustment of reference wages. If the SRPC has some negative slope then any tendency to a deceleration of wages would be held up by sluggishness in the rate of reference wage inflation. Barring any dramatic circumstances that would cause workers to take a good look at their conditions, such as a threat of plant closure, it seems reasonable to expect that downward adjustment of reference levels is sluggish because the literature suggests that reference wages are influenced by past actual wages, other workers actual wages and the firm's capacity to pay. ${ }^{17}$

Compare the dynamics implied by reference wage determination with the dynamics of the Neoclassical approach. In the Neoclassical approach, workers are concerned with their supply price of labour and that price is determined by their preferences, 'set in concrete' so to speak. Workers will be prepared to work at wages which exceed their supply price and so will be prepared to participate in a process that, in response to a plentiful supply of labour, chases down wages. Workers by assumption are not influenced by their past wages, their idea of the wages of others or by the firm's capacity to pay. However, this chasing down does not appear to happen. Thus, the lack of deceleration in periods of high unemployment casts doubt on the Neoclassical approach.

Turning to the other dynamic, acceleration, the steepness of the SRPC at low rates of unemployment, at rates less than umin, is a force for acceleration. However, we find that past experience of accelerationist tendencies in wages at rates of unemployment less than umin, that is low-unemployment periods, reveal mixed tendencies. For both the US and Australia there were pronounced tendencies for nominal ULC inflation to be increasing in low-unemployment periods before the mid 1970s, consistent with the acceleration hypothesis. However, this tendency does not show up for the low-unemployment periods after the mid 1970s, which are 1972Q2 to 1979Q3 for Australia and 1993Q3 to 2000Q4 for the US.

17. This sluggish adjustment of the reference wage is an example of Palley's emphasis on the importance of the incorporation of inflation expectations rather than simply the formation of inflation expectations - see Palley (2012). 
The tendency towards acceleration is usually inferred from positing a sustained excess demand for labour, under which both employers and employees see advantage in increasing wages. However, if unions are setting the inflationary pace when unemployment rates are less than umin then employers will not have a direct benefit from increasing wages; it is a battle with the unions. Thus, rates of unemployment below umin may not be as accelerationist as suggested by the implications of sustained excess demand. This consideration is particularly relevant for the Australian economy in its low-unemployment period in the 1970s.

In addition to the benefit of resolving the wage-deflation puzzle, allowing for loss aversion in our specification of the wage-inflation-unemployment process results in an improved understanding of the role of labour supply factors. The loss-aversion approach implies that umin would be influenced by labour supply factors. We consider the unemployment benefit replacement ratio and union density to be a proxy for worker power. Our estimates of these influences are well determined. ${ }^{18}$ The average size of the 95 per cent confidence interval on umin over our estimation periods is 0.87 and 0.75 for the US and Australia respectively compared with 1.65 and 1.06 for the BCS NAIRU, and 8.41 and 6.13 for the natural rate model. Furthermore, the influence of labour supply factors on umin are substantial. For example, over the sample period, variation in the labour supply factors causes a range of values of umin of 5.4 percentage points for the US and 5.1 percentage points for Australia. ${ }^{19}$

\section{REFERENCES}

Akerlof, G.A., W.T. Dickens and G.L. Perry (1996), 'The macroeconomics of low inflation', Brookings Papers on Economic Activity, 1, 1-76.

Barro, R. (2010), 'The folly of subsidizing unemployment', The Wall Street Journal, 30 August. Benigno, G. and L. Fornaro (2015), 'Stagnation traps', CEPR Discussion Paper No DP11074. Bewley, T.F. (1999), Why Wages Don't Fall During a Recession, Cambridge, MA: Harvard University Press.

Bhaskar, V. (1990), 'Wage relativities and the natural range of unemployment', Economic Journal, 100(400), 60-66.

Blanchard, O. (2018), 'Should we reject the natural rate hypothesis?', Journal of Economic Perspectives, 32(1), 97-120.

Blanchard, O.J. and L.H. Summers (1986), 'Hysteresis and the European unemployment problem', in S. Fischer (ed.), NBER Macroeconomics Annual 1986, Volume 1, Cambridge, MA: MIT Press, pp. 15-90.

18. Our estimates show that for the US, umin is also influenced by demographic factors, that is the proportions of teenage, female and black workers in the labour force.

19. Comparing the US and Australia, there are some substantial differences in the estimates of parameter values; see Table 1. In the US, umin is more responsive to unemployment benefits and union density than in Australia. Also, ULC inflation is more responsive to unemployment in the US compared with Australia. More investigation may reveal whether these estimates reflect structural differences between the economies. A panel-data approach applying our range model to several economies may be valuable. Also, if the factors driving our umin estimate of 4.0 per cent for the end of our data period, September 2017, have not changed then inflation in the US should be increasing at the present time because the actual rate of unemployment, 3.5 per cent in November 2019, would be less than umin. This suggests investigating refinements to our estimating equation for umin, for instance the impact of the increased monopsony power of employers documented by Krueger (2018). 
Blanchard, O., E. Cerruti and L. Summers (2015), 'Inflation and activity: two explorations and their monetary policy implications', IMF Working Paper, WP/15/230.

Carmichael, L. (1985), 'Equilibrium unemployment: comment', American Economic Review, 75(5), 1213-1214.

Chan, J., T. Clark and G. Koop (2018), 'A new model of inflation, trend inflation and long-run inflation expectations', Journal of Money, Credit and Banking, 50(1), 5-53.

Chua, C.L. and T. Robinson (2018), 'Why has Australian wages growth been so slow? A Phillips curve perspective', Economic Record, 94(Special Issue), 11-32.

Davis, S. and T.V. Wachter (2011), 'Recessions and the cost of job loss', Brookings Papers on Economic Activity, 2, 1-72.

DeLong, J.B. and L.H. Summers (2012), 'Fiscal policy in a depressed economy', Brookings Papers on Economic Activity, Spring, 233-297.

Gordon, R.J. (1990), 'What is New Keynesian economics?', Journal of Economic Literature, 28(3), 1115-1171.

Gordon, R.J. (1997), 'The time-varying NAIRU and its implications for economic policy', Journal of Economic Perspectives, 11(1), 11-32.

Gordon, R.J. (1998), 'Foundations of the Goldilocks economy: supply shocks and the timevarying NAIRU', Brookings Papers on Economic Activity, 2, 297-346.

Gordon, R.J. (2018), 'Friedman and Phelps on the Phillips curve viewed from a half century's perspective', Review of Keynesian Economics, 6(4), 425-436.

Gruen, D., A. Pagan and C. Thompson (1999), 'The Phillips curve in Australia', Journal of Monetary Economics, 44, 223-258.

Holden, S. and F. Wulfsberg (2009), 'How strong is the macroeconomic case for downward real wage rigidity?', Journal of Monetary Economics, 56, 605-615.

Isaac, J.E. (2018), 'Why are Australian wages lagging and what can be done about it?', Australian Economic Review, 51(2), 175-190.

Kahneman, D. and A. Tversky (1979), 'Prospect theory: an analysis of decision under risk', Econometrica, 47(2), 263-291.

Kahneman, D., J.L. Knetsch and R. Thaler (1986), 'Fairness as a constraint on profit seeking: entitlements in the market', American Economic Review, 76(4), 728-741.

Keynes, J.M. (1936), The General Theory of Employment, Interest and Prices, London: Macmillan.

Koszegi, B. and M. Rabin (2006), 'A model of reference-dependent preferences', Quarterly Journal of Economics, 121(4), 1133-1165.

Krueger, A.B. (2018), 'Reflections on dwindling worker bargaining power and monetary policy', Luncheon Address at the Jackson Hole Economic Symposium, 24 August.

Layard, R., S.J. Nickell and R. Jackman (1991), Unemployment: Macroeconomic Performance and the Labour Market, Oxford: Oxford University Press.

Lye, J.N. and I.M. McDonald (2006), 'An evaluation of unemployment policy in Australia using the range of equilibria', Australian Economic Review, 9(3), 239-256.

Lye, J.N., I.M. McDonald and H. Sibly (2001), 'An estimate of the range of equilibrium rates of unemployment for Australia', Economic Record, 77(236), 35-50.

Marinescu, I. (2017), 'The general equilibrium impact of unemployment insurance: evidence from a large online job board', Journal of Public Economics, 150, 14-29.

McDonald, I.M. (1987), 'Customer markets, trade unions and stagflation', Economica, 54(May), 139-153.

McDonald, I.M. (1991), 'Insiders and trade union wage bargaining', Manchester School of Economics \& Social Studies, LIX(December), 395-407.

McDonald, I.M. (2019), 'John Maynard Keynes, Joan Robinson and the prospect theory approach to money wage determination', Metroeconomica, 70(1), 45-67.

McDonald, I.M. and H. Sibly (2005), 'The diamond of macroeconomic equilibria and the noninflationary expansion', Metroeconomica, 56(3), 393-409.

Palley, T.I. (1990), 'A theory of downward wage rigidity: job commitment costs, replacement costs and tacit coordination', Journal of Post Keynesian Economics, 12(Spring), 466-486. 
Palley, T.I. (2012), 'The economics of the Phillips curve: formation of inflation expectations versus incorporation of inflation expectations', Structural Change and Economic Dynamics, 23, 221-230.

Phillips, A.W.H. (1958), 'The relation between unemployment and the rate of change of money wage rates in the United Kingdom, 1861-1957', Economica, 25, 283-299.

Robinson, J. (1937), Essays in the Theory of Employment, London: Macmillan.

Romer, C.D. (1996), 'Inflation and the growth rate of output', NBER Working Paper, No 5575.

Schultze, C.L. (1959), 'Recent inflation in the United States', in Joint Economic Committee (ed.), Employment, Growth and the Price Levels, Study Paper No 1, Washington, DC: Government Printing Office, pp. 1-137.

Shafir, E., P. Diamond and A. Tversky (1997), 'Money illusion', Quarterly Journal of Economics, CXII, 341-374.

Shapiro, C. and J.E. Stiglitz (1984), 'Equilibrium unemployment as a worker discipline device', American Economic Review, 74(3), 433-444.

Shapiro, C. and J.E. Stiglitz (1985), 'Can unemployment be involuntary?', American Economic Review, 75(5), 1215-1217.

Sibly, H. (2002), 'Loss averse customers and price inflexibility', Journal of Economic Psychology, 23(4), 521-538.

Tobin, J. (1972), 'Inflation and unemployment', The American Economic Review, 62(1/2), 1-18.

Woglom, G. (1982), 'Unemployment equilibrium with rational expectations', Quarterly Journal of Economics, XCVIII(February), 89-107. 


\section{APPENDIX 1 A SIMPLE MODEL OF THE RANGE OF EQUILIBRIA COMBINING BARGAINING AND EFFICIENCY WAGES}

To capture bargaining, specify the union's objective as the difference between utility from working and the utility from the reservation wage, that is:

$$
\Xi^{i}=U^{i}-U^{R E S}=W^{\beta_{1}}\left(W / W^{R E F}\right)^{\beta_{2}^{i}}-\left(W^{R E S}\right)^{\beta_{1}} \text { for } i=\{+,-\},
$$

where these two utilities are determined by:

$$
\left\{\begin{array}{l}
U^{+}=W^{\beta_{1}}\left(W / W^{R E F}\right)^{\beta_{2}^{+}} \text {for } W \geq W^{R E F} \\
U^{-}=W^{\beta_{1}}\left(W / W^{R E F}\right)^{\beta_{2}^{-}} \text {for } W<W^{R E F} \\
U^{R E S}=\left(W^{R E S}\right)^{\beta_{1}}
\end{array}\right\} \text { with } 0<\beta_{1}<1 \text { and } 0<\beta_{2}^{+}<\beta_{2}^{-}<1,
$$

where $W=$ money wage, $W^{R E F}=$ reference money wage and $W^{R E S}=$ reservation money wage. Loss aversion influences the utility from working. $0<\beta_{2}^{+}<\beta_{2}^{-}<1$ implies that the sensitivity of utility to wages below the reference wage is greater than the sensitivity of utility to wages above the reference wage. There is a kink in the utility function at $W=W^{R E F}$. Note that for simplicity, following Layard et al. (1991), the union cares only about the wage.

To capture efficiency wages, the production function is written:

$$
Y=A e L^{\alpha}
$$

where $Y=$ output, $A=$ base level efficiency, $L=$ employment and $e=$ the impact of wage outcomes on the efficiency of labour, which is specified to follow:

$$
\begin{aligned}
& e=\left(\frac{W}{W^{R E F}}\right)^{\theta^{i}}-K \text { for } i=\{+,-\} \text { as } W \geq W^{R E F} \text { or } W<W^{R E F} \\
& \text { with } 0<\theta^{+}<\theta^{-}<1 \text { and } K<1 .
\end{aligned}
$$

Due to loss aversion, the efficiency function is kinked at $W=W^{R E F}$.

The profits of the firm, $\Pi$, is:

$$
\Pi=P Y-W L=C \bar{P}\left(A\left[\left(\frac{W}{W^{R E F}}\right)^{\theta^{i}}-K\right]\right)^{1-h} L^{\alpha(1-h)}-W L,
$$

where the demand function for the firm's output is

$$
P-C \bar{P} Y^{-h}
$$

where $P=$ firm's price and $\bar{P}=$ the aggregate price level. 
The wage is chosen to maximise the Nash maximand

$$
\begin{aligned}
& \Omega=\Xi^{\phi} \Pi^{1-\phi} \\
& =\left[W^{\beta_{1}}\left(W / W^{R E F}\right) \beta_{2}^{i}-\left(W^{R E S}\right)^{\beta_{1}}\right]^{\phi}\left[\left(C \bar{P}\left[A\left(\frac{W}{W^{R E F}}\right)^{\theta^{i}}-K\right]\right)^{1-h} L^{\alpha(1-h)}-W L\right]^{1-\phi},
\end{aligned}
$$

subject to the 'right to manage' constraint

$$
W=\alpha(1-h) C \bar{P}\left(A\left[\left(\frac{W}{W^{R E F}}\right)^{\theta^{i}}-K\right]\right)^{1-h} L^{\alpha(1-h)-1} .
$$

This choice constrains the equilibrium wage to lie between limits determined by two values, $\left\{k^{+}, k^{-}\right\}$of the mark-up of the wage on the reservation wage, that is:

$$
\frac{W^{i}}{W^{R E S}}=\left(\frac{1}{1-\frac{\phi}{1-\phi} \frac{\left(\beta_{1}+\beta_{2}^{i}\right) \frac{1}{\alpha(1-h)}-1}{1-\frac{\theta^{i}}{\alpha(1-K)}}}\right)^{\frac{1}{\beta_{1}}}=k^{i} \text { for } i=\{+,-\} .
$$

Note that through $0<\beta_{2}^{+}<\beta_{2}^{-}<1$ and $0<\theta^{+}<\theta^{-}<1$, loss aversion implies $k^{-}>k^{+}$.

In general equilibrium, macroeconomic closure implies a range of equilibria and rates of unemployment. To derive the range of equilibria, specify the reservation wage as a linear function of alternative wage, $W^{A}$, and the unemployment benefit, $B$, weighted by the probability of getting employment, $r$, as follows:

$$
W^{R E S}=\rho W^{A}+(1-\rho) B
$$

In general equilibrium, $W^{A}=W$. Assuming that the unemployment benefit is set as a proportion, $b$, of the wage, as $B=b W$, then $\frac{W}{W^{R E S}}=\frac{1}{\rho(1-b)+b}$ and so $W^{i}=k^{i} W^{R E S}$ implies

$$
\rho^{i}=\frac{\frac{1}{k^{i}}-b}{1-b} \leq 1 \text { as } k^{i} \geq 1 \text { for } i=\{+,-\} \text { and } k^{+}<k^{-} \rightarrow \rho^{+}>\rho^{-} .
$$

Using $u=1-\frac{L}{L^{S}}$, where $L^{S}=$ aggregate labour supply, $\rho=1-u$ and so

$$
u^{i}=1-\rho^{i}=\frac{1-\frac{1}{k^{i}}}{1-b} \text { for } i=\{+,-\} \rightarrow u^{i} \geq 0 \text { as } k^{i} \geq 1 .
$$

Thus, loss aversion implies a range of equilibrium rates of unemployment given by $k^{+}<k^{-} \rightarrow u^{\min }=u^{+} \leq u \leq u^{-}=u^{\max }$. 


\section{APPENDIX 2 DATA SOURCES AND DESCRIPTIVE STATISTICS}

\section{A2.1 US}

Unemployment: OECD harmonised unemployment rate.

Unemployment benefit ratio: 1966Q2 to 2000Q4; OECD. 2001Q1 to 2017Q4; OECD average of net replacement rates over 60 months of unemployment, interpolated from annual data.

Union density: BLS. Interpolated from annual data.

Female/non-white composite: A composite from a principal component analysis of the female and non-white labour force shares, from BLS.

Teen: Teenage labour force share, from BLS.

Unit labour costs: Non-farm Business Sector: Unit Labor Cost, Index $2009=100$, Quarterly, Seasonally adjusted, from OECD.

CPI: Consumer Price Index: All Items Excluding Food and Energy for the United States, Not seasonally adjusted, from FRED.

Expected inflation: From Chan et al. (2018), available at: http://joshuachan.org/ research.html.

Manufacturing employment share: Employment in manufacturing as a share of total employment: OECD Main Economic Indicators converted from monthly. Series smoothed by an HP trend.

\section{A2.2 Australia}

All data is quarterly seasonally adjusted unless indicated. ABS: Australian Bureau of Statistics; RBA: Reserve Bank of Australia; BLS: Bureau of Labor Statistics; FRED: Federal Reserve Economic Data.

Unemployment: ABS NIF Database.

Unemployment benefit replacement ratio: Unemployment benefits divided by after-tax average weekly earnings, males. Supplied by RBA and Australian Treasury.

Union density: Union members divided by total employment. ABS 6310.0; interpolated from annual data for 2003Q3 to 2017Q3 with gaps in 2015 and 2017.

Unit labour costs: Wages per person divided by non-farm productivity per person. 1964Q1 to 1985Q2, as used in Gruen et al. (1999). 1985Q3 to 2017Q3; ULC nonfarm ABS 5206.0 table 42.

CPI: 1964Q1 to 1982Q4, from Gruen et al. (1999). 1982Q3 to 2017Q3, from RBA. Expected inflation: Average annual inflation rate implied by the difference between ten-year nominal bond yield and ten-year inflation indexed bond yield. 1964Q2 to 1998Q4, from Gruen et al. (1999). 1999Q1 to 2017Q3, from RBA.

Manufacturing employment share: Manufacturing employment divided by total employment. 1966Q3 to 1985Q1, from RBA. 1985Q2 to 2017Q3, interpolated to quarterly from annual frequency. 1985Q2 to 2017Q3; ABS 6291.0.55.003. Series smoothed by an HP trend. 

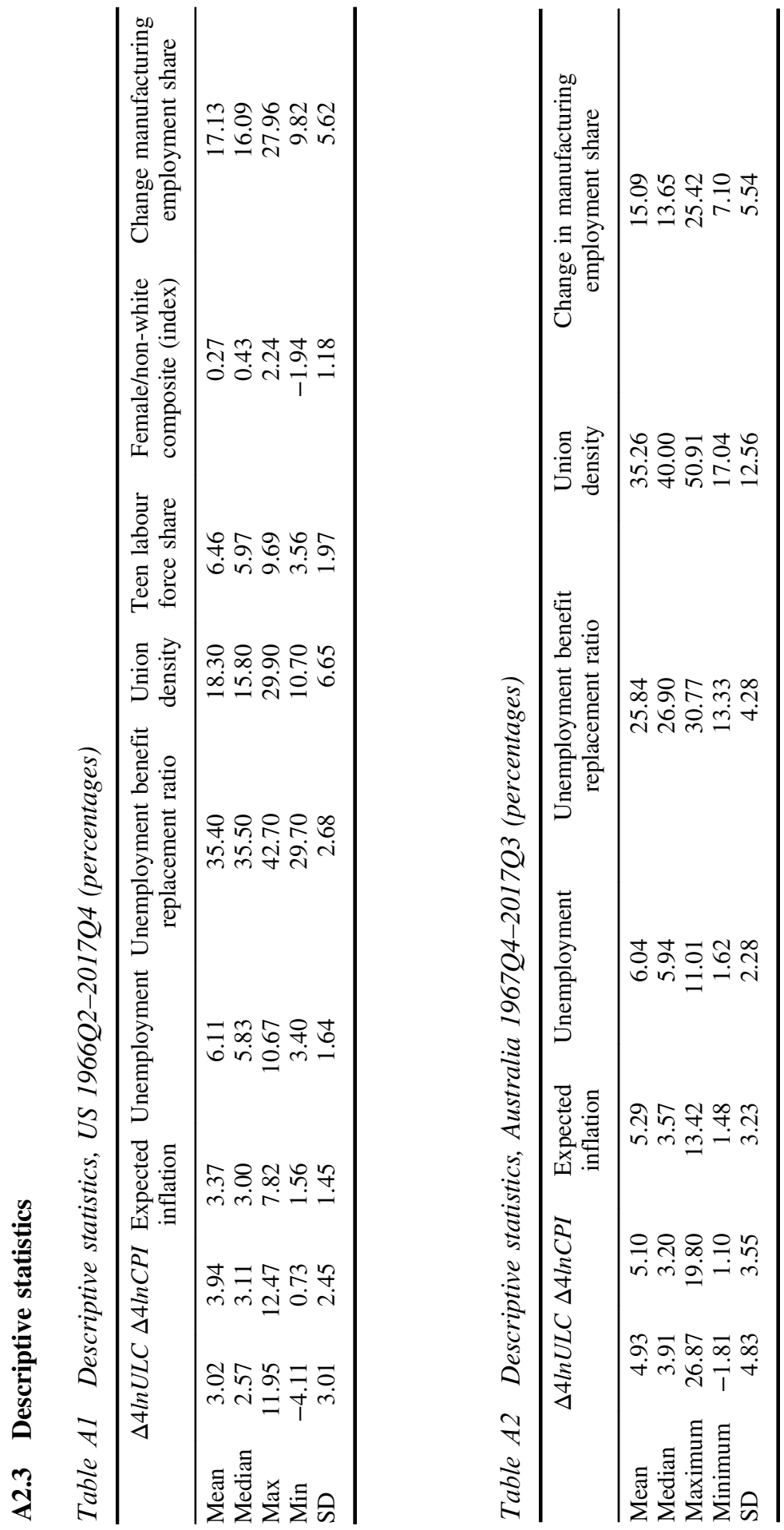
42 Review of Keynesian Economics, Vol. 9 No. 1

\section{A2.4 Patterns of the measures of inflation}

15

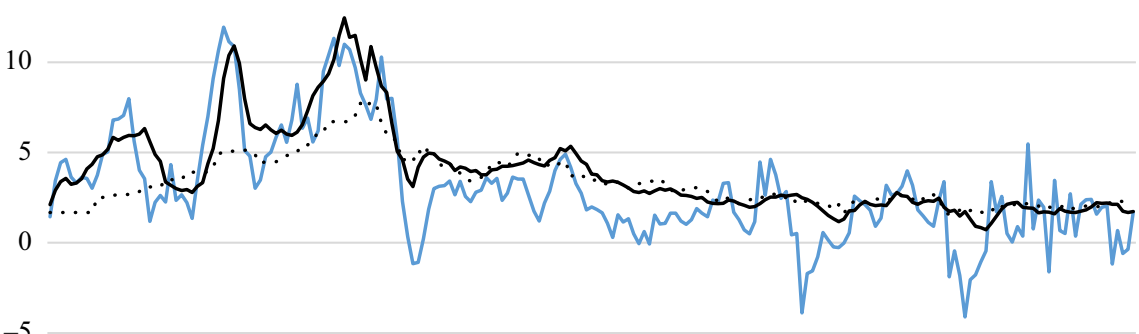

$-5$

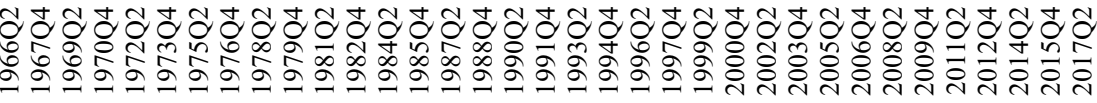
$\checkmark 4 \ln U L C \%-\Delta 4 \ln C P I \% \quad \ldots \ldots$ Expected inflation $\%$

Figure A1 US, $1966 Q 2$ to $2017 Q 4$

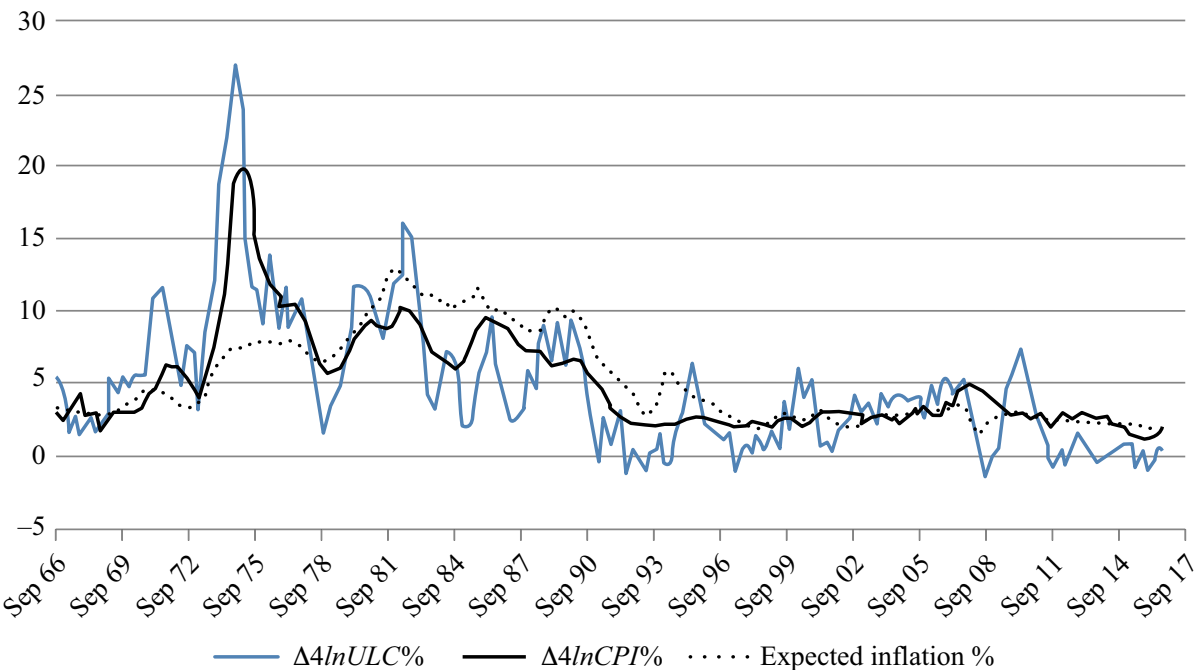

Figure A2 Australia, 1966Q3 to 2017Q3 